\title{
Neogene 'horn Sharks' Heterodontus (Chondrichthyes: Elasmobranchii) from the Southeastern Pacific and Their Paleoenvironmental Significance
}

\author{
Partarrieu, Diego ; Villafaña, Jaime ; Pinto, Luisa ; Amaro Mourgues, F ; Oyanadel-Urbina, Pablo ; \\ Rivadeneira, Marcelo ; Carrillo-Briceño, Jorge
}

\begin{abstract}
Horn sharks (Elasmobranchii: Heterodontus Blainville) correspond to a genus of chondrichthyan fishes, mostly distributed in warmtemperate to tropical regions of the Pacific and Indian Oceans. The fossil record shows that, in contrast to its current distribution, horn sharks were widely distributed both in the eastern Pacific and western Atlantic during the Neogene, being subsequently extirpated from some of these areas. In this contribution, we describe new Heterodontus teeth from three Pliocene localities in the Coquimbo Region, in north-central Chile, and make an extensive revision of the fossil record of the genus in the Americas, in order to specify the timing of their extirpation in the southeastern Pacific and discuss the possible causes of this event. The new specimens described herein belong to a species with a Heterodontus francisci type dentition. Our analysis suggest that the removal of horn sharks occurred in the context of a general faunal turnover in the transition from Pliocene to Pleistocene, and that it was probably controlled by an interplay between the oceanographic, tectono-eustatic and ecological changes occurred in the region at that time. Key words. Miocene. Pliocene. Pleistocene. America. Chile. Fossil. Elasmobranchs. Extirpation. Resumen. 'TIBURONES CORNUDOS' HETERODONTUS (CHONDRICHTHYES: ELASMOBRANCHII) NEÓGENOS DEL PACÍFICO SURORIENTAL Y SU SIGNIFICADO PALEOAMBIENTAL. Los tiburones cornudos (Elasmobranchii: Heterodontus Blainville) conforman un género de peces condrictios, principalmente distribuidos en regiones templadocálidas a tropicales de los océanos Pacífico e Índico. El registro fósil muestra que, en contraposición a su distribución actual, durante el Neógeno los tiburones cornudos se distribuyeron ampliamente tanto en el Pacífico oriental como en el Atlántico occidental, siendo posteriormente extirpados de algunas de estas áreas. En este trabajo, describimos nuevos dientes Heterodontus de tres localidades del Plioceno en la Región de Coquimbo, en el centro-norte de Chile, y realizamos una extensa revisión del registro fósil del género en las Américas, para precisar el momento en que se produjo su extirpación en el Pacífico suroriental y discutir las posibles causas de este acontecimiento. Los nuevos materiales aquí descritos pertenecen a una especie con dentición del tipo Heterodontus francisci. Nuestros análisis sugieren que la extirpación de los tiburones cornudos se produjo en el contexto de una renovación general de la fauna en la transición del Plioceno al Pleistoceno, y que fue probablemente controlada por una interacción entre los cambios oceanográficos, tectonoeustáticos y ecológicos ocurridos en la región durante aquellos tiempos. Palabras clave. Mioceno. Plioceno. Pleistoceno. América. Chile. Fósil. Elasmobranquios. Extirpación
\end{abstract}

DOI: https://doi.org/10.5710/amgh.19.10.2018.3202 


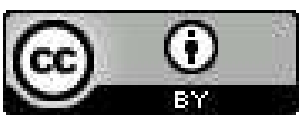

The following work is licensed under a Creative Commons: Attribution 4.0 International (CC BY 4.0) License.

Originally published at:

Partarrieu, Diego; Villafaña, Jaime; Pinto, Luisa; Amaro Mourgues, F; Oyanadel-Urbina, Pablo; Rivadeneira, Marcelo; Carrillo-Briceño, Jorge (2018). Neogene 'horn Sharks' Heterodontus (Chondrichthyes: Elasmobranchii) from the Southeastern Pacific and Their Paleoenvironmental Significance. Ameghiniana, 16:651-667.

DOI: https://doi.org/10.5710/amgh.19.10.2018.3202 


\title{
Soft-tissue evidence for homeothermy and crypsis in a Jurassic ichthyosaur
}

Johan Lindgren ${ }^{1 *}$, Peter Sjövall ${ }^{2}$, Volker Thiel ${ }^{3}$, Wenxia Zheng ${ }^{4}$, Shosuke Ito ${ }^{5}$, Kazumasa Wakamatsu ${ }^{5}$, Rolf Hauff ${ }^{6}$, Benjamin P. Kear ${ }^{7}$, Anders Engdahl ${ }^{8}$, Carl Alwmark ${ }^{1}$, Mats E. Eriksson ${ }^{1}$, Martin Jarenmark ${ }^{1}$, Sven Sachs ${ }^{9}$, Per E. Ahlberg ${ }^{10,11}$, Federica Marone $^{12}$, Takeo Kuriyama ${ }^{13,14}$, Ola Gustafsson ${ }^{15}$, Per Malmberg ${ }^{16}$, Aurélien Thomen ${ }^{17}$, Irene Rodríguez-Meizoso ${ }^{18}$, Per Uvdal ${ }^{19}$, Makoto Ojika ${ }^{20}$ \& Mary H. Schweitzer ${ }^{1,4,21}$

\begin{abstract}
Ichthyosaurs are extinct marine reptiles that display a notable external similarity to modern toothed whales. Here we show that this resemblance is more than skin deep. We apply a multidisciplinary experimental approach to characterize the cellular and molecular composition of integumental tissues in an exceptionally preserved specimen of the Early Jurassic ichthyosaur Stenopterygius. Our analyses recovered still-flexible remnants of the original scaleless skin, which comprises morphologically distinct epidermal and dermal layers. These are underlain by insulating blubber that would have augmented streamlining, buoyancy and homeothermy. Additionally, we identify endogenous proteinaceous and lipid constituents, together with keratinocytes and branched melanophores that contain eumelanin pigment. Distributional variation of melanophores across the body suggests countershading, possibly enhanced by physiological adjustments of colour to enable photoprotection, concealment and/or thermoregulation. Convergence of ichthyosaurs with extant marine amniotes thus extends to the ultrastructural and molecular levels, reflecting the omnipresent constraints of their shared adaptation to pelagic life.
\end{abstract}

With their dolphin-like external form, the Mesozoic ichthyosaurs are icons of evolution. Although finds from the 18th and 19th centuries led to their recognition as prehistoric oceangoing reptiles, it was not until the discovery of articulated skeletons with complete body outlines that the extent of this anatomical specialization towards an obligate marine existence was fully appreciated. These specimens, from the Holzmaden area of Germany, reveal a combination of paired flippers, a triangular dorsal fin and a lunate tail that would have enabled efficient hydrodynamic manoeuvring. Derived ichthyosaurs (parvipelvians) were thus notably similar in appearance to extant pelagic cruisers such as odontocete whales and lamnid sharks ${ }^{1}$.

Despite this textbook example of evolutionary convergence, the nature of the residues that form the body contours-and the diagenetic processes that led to their preservation-remain incompletely understood. Various competing interpretations have suggested that these remnants comprise genuine soft parts (consisting either of carbonized and/or phosphatized integument, and superficial musculature or connective tissue $\mathrm{e}^{2,3}$ ), in situ transformed organic matter such as adipocere ${ }^{4,5}$, or microorganismal replacement structures ${ }^{1,6}$. Creases described as dermal tensile fibres have also been documented ${ }^{5}$, but alternatively dismissed as sedimentary cracks and tool marks ${ }^{7}$.

Here we use an integrated ultrastructural and molecular investigation of a chemically untreated specimen (MH 432; Urweltmuseum Hauff, Holzmaden, Germany) of the Early Jurassic (Toarcian) parvipelvian Stenopterygius to resolve these long-standing contentions. This fossil reveals endogenous cellular, sub-cellular and biomolecular constituents within relict skin and subcutaneous tissue (Figs. 1-5 and Extended Data
Figs. 1-7); we also document a possible internal organ trace, which we interpret as the liver (Extended Data Fig. 8). Finally, we provide comparative data obtained from the cutis and subcutis of modern marine tetrapods (Extended Data Fig. 9).

\section{The fossil and experimental design}

The soft-tissue residues of MH 432 comprise a buff-coloured to black coating that adheres to the outside of the postcranium, but also extends some distance beyond the periphery of the bones to produce a bedding-parallel outline of the animal (Fig. 1 and Extended Data Fig. 1a). A second, superficially amorphous material occurs as light beige patches external to this film in the abdominal region (Extended Data Fig. 1b), whereas fibrous matter (Extended Data Fig. 1c) and the red-brown liver trace are located inside the rib cage (Fig. 1 and Extended Data Fig. 1b).

We conducted examinations under regular (Fig. 1a and Extended Data Fig. 1a-c) and ultraviolet light (Extended Data Fig. 1d-m), as well as through synchrotron rapid-scanning $\mathrm{X}$-ray fluorescence (Fig. 1c and Extended Data Fig. 1n, o). The resulting data enabled us to assess the elemental composition of the soft parts, and were also used to identify areas that were suitable for in-depth molecular and imaging investigations. Tissue and sediment samples (Fig. 1b) were collected with sterile instruments and distributed to multiple institutions for independent cross-referencing analyses. Some samples were subjected to chemical extraction, while others were first examined untreated, and then again after treatment with ethylenediaminetetraacetic acid (EDTA).

\footnotetext{
${ }^{1}$ Department of Geology, Lund University, Lund, Sweden. ${ }^{2}$ RISE Research Institutes of Sweden, Chemistry and Materials, Borås, Sweden. ${ }^{3}$ Geobiology, Geoscience Centre, University of Göttingen, Göttingen, Germany. ${ }^{4}$ Department of Biological Sciences, North Carolina State University, Raleigh, NC, USA. ${ }^{5}$ Department of Chemistry, Fujita Health University School of Health Sciences, Toyoake, Japan. ${ }^{6}$ Urweltmuseum Hauff, Holzmaden, Germany. ${ }^{7}$ Museum of Evolution, Uppsala University, Uppsala, Sweden. ${ }^{8}$ MAX-IV laboratory, Lund University, Lund, Sweden. ${ }^{9}$ Naturkunde-Museum Bielefeld, Abteilung Geowissenschaften, Bielefeld, Germany. ${ }^{10}$ Science for Life Laboratory, Uppsala University, Uppsala, Sweden. ${ }^{11}$ Department of Organismal Biology, Uppsala University, Uppsala, Sweden. ${ }^{12}$ Swiss Light Source, Paul Scherrer Institute, Villigen, Switzerland. ${ }^{13}$ Institute of Natural and Environmental Sciences, University of Hyogo, Hyogo, Japan. ${ }^{14}$ Wildlife Management Research Center, Hyogo, Japan. ${ }^{15}$ Department of Biology, Lund University, Lund, Sweden. ${ }^{16}$ Department of Chemistry and Chemical Engineering, Chalmers University of Technology, Gothenburg, Sweden. ${ }^{17}$ Department of Chemistry and Molecular Biology, University of Gothenburg, Gothenburg, Sweden. ${ }^{18}$ Centre for Analysis and Synthesis, Department of Chemistry, Lund University, Lund, Sweden. ${ }^{19}$ Chemical Physics, Department of Chemistry, Lund University, Lund, Sweden. ${ }^{20}$ Department of Applied Biosciences, Graduate School of Bioagricultural Sciences, Nagoya University,

Nagoya, Japan. ${ }^{21}$ North Carolina Museum of Natural Sciences, Raleigh, NC, USA. *e-mail: johan.lindgren@geol.lu.se
} 

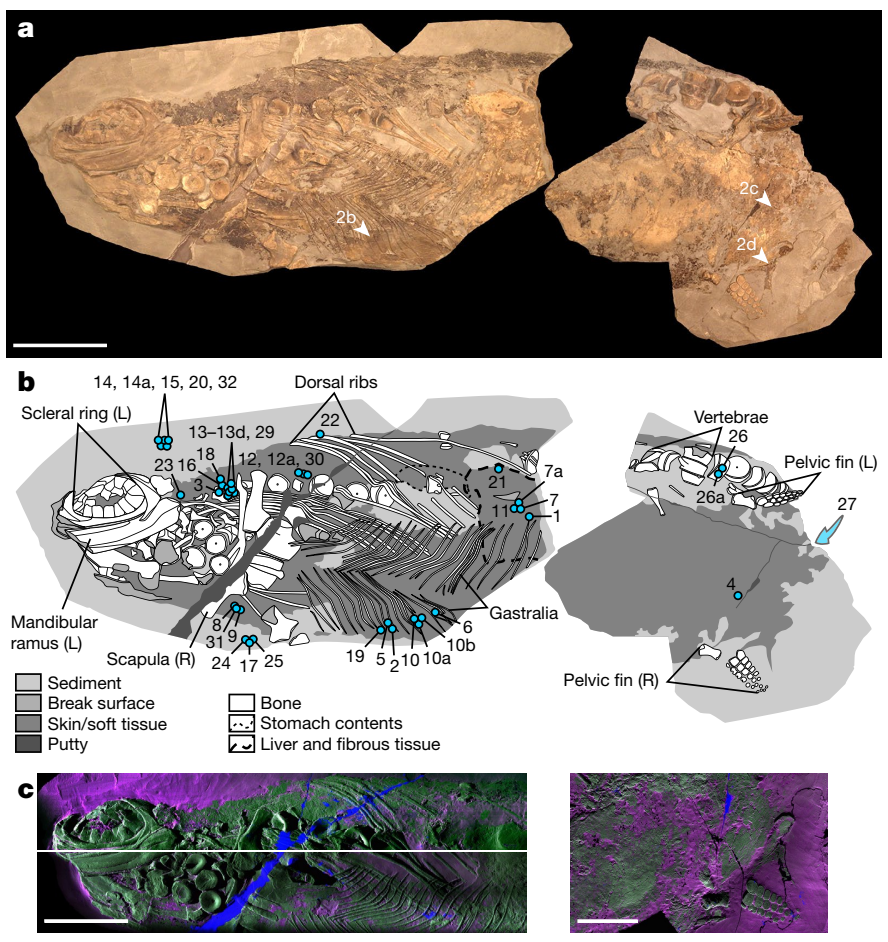

Fig. 1 | Stenopterygius specimen MH 432. a, b, Photographic (a) and diagrammatic (b) representation of the fossil in oblique ventral view. Arrowheads indicate enlargements shown in Fig. 2b-d; numerals (blue circles) denote the locations from which samples were taken (sample 27 was collected from the underside of the slab). L, left-hand skeletal element; R, right-hand skeletal element. c, Synchrotron rapid-scanning $\mathrm{X}$-ray fluorescence (SRS-XRF) false-colour images showing the spatial distribution of potassium (magenta), calcium (green) and titanium (blue). Extended Data Fig. 1 presents additional SRS-XRF maps and photographs of $\mathrm{MH} 432$ under regular and ultraviolet light. Scale bars, $5 \mathrm{~cm}$ (c right), $10 \mathrm{~cm}$ (a, c left).

\section{Cutis and melanophores}

The soft tissues of the body outline are preserved as a mineralized, semi-continuous covering (Fig. 1 and Extended Data Fig. 1). No scales or scutes are evident (Fig. $2 \mathrm{a}-\mathrm{d}$ ). Instead, the external surface is smooth, and was presumably comparable in life to the rubbery ${ }^{8,9}$ skin of extant cetaceans (Fig. 2q) and adult individuals of the leatherback sea turtle, Dermochelys coriacea (Fig. 2s). Wrinkles and ripples (Fig. 2c, d) closely resemble those that have been observed to distort decomposing integument following loss of structural integrity (Fig. 2r). Demineralization, and subsequent histological and microscopic examination, evinced a multi-layered subsurface architecture (Fig. 2e-p and Extended Data Fig. 2a-e) that corresponds to the laminated epidermis and dermis of modern tetrapods ${ }^{10,11}$ (Fig. 2t). Sparse oval perforations about $70 \mu \mathrm{m}$ in diameter pass through the cutis (Fig. 2i, j), and are tentatively interpreted as pores.

The approximately $100-\mu$ m-thick epidermis retains cell-like structures that are likely to represent preserved melanophores (Fig. 3 and Extended Data Fig. 3) and keratinocytes that were undergoing differentiation $^{11,12}$ (Fig. $2 \mathrm{~m}-\mathrm{o}$ ). The outer section of the skin can be further divided into an upper stratum corneum, characterized by stratified squamous cells (Fig. 2m-o and Extended Data Fig. 2b), and a deeper unit that contains polyhedral-to-oblate cellular bodies that become increasingly flattened towards the external surface (Fig. 2o and Extended Data Fig. 2d). This lower part is reasonably interpreted as vestiges of the middle and basal layers of the epidermis, comprising the stratum intermedium and stratum germinativum, respectively; the junction between these layers is not well-defined in $\mathrm{MH} 432$. Vertical extensions at the epidermal-dermal interface form a regularly arranged series of interlocking ridges that run parallel to the longitudinal axis of the body (Fig. 2f and Extended Data Fig. 2a). This microstructure is consistent with the basement membrane of extant tetrapods ${ }^{9}$, and overlies an approximately $80-\mu \mathrm{m}$-thick band of connective tissue fibres that constitutes the superficial dermis (Fig. 2l, p and Extended Data Fig. 2e).

The fossilized pigment cells have long dendritic processes and a granular internal filling (Fig. 3, Extended Data Fig. 3 and Supplementary Video 1). They are virtually identical in size (about $10 \mu \mathrm{m}$ in diameter, excluding the external projections), geometry and inner fabric to the branched melanophores of extant reptiles (Fig. 31-q). Our chemical identification of eumelanin (Fig. 3r, s and Extended Data Fig. 3f) further suggests that the granular content represents remnant melanosome organelles (see Supplementary Information).

\section{Preservation of cutis}

We posit that the cutis of $\mathrm{MH} 432$ was fossilized through partial replication in authigenic calcium phosphate ${ }^{13}$ (Fig. 1c and Extended Data Figs. 1n, o, 2f, g), an eogenetic mineralization process that enabled the retention of three-dimensional cellular morphologies. However, our experimental removal of the inorganic phase revealed a second preservational mode: in situ molecular transformation (geopolymerization or kerogenization), which is a mechanism whereby labile-to-relatively recalcitrant organic compounds are altered into stable macromolecules by (re-)polymerization, polycondensation and/or defunctionalization reactions ${ }^{14-16}$. Energy-dispersive X-ray microanalysis (EDX), timeof-flight secondary ion mass spectrometry (ToF-SIMS), nanoscale secondary ion mass spectrometry (NanoSIMS), pyrolysis-gas chromatography with mass spectrometry (Py-GC/MS) and infrared microspectroscopy collectively confirmed the primarily organic composition of the artificially released (and still somewhat flexible; Supplementary Video 2) tissues and cells as being dominated by aliphatic and aromatic hydrocarbon moieties (Fig. 4a, d and Extended Data Figs. 2h, 4a, 5). Such geopolymers are likely to be diagenetic transformation products from a variety of compounds. Although specific precursor molecules are difficult to identify, an endogenous lipid source for at least some of them can reasonably be inferred from the inherent chemical stability of lipid hydrocarbon skeletons, and their demonstrated ability to polymerize in situ; this constitutes a major factor in organic preservation ${ }^{14-16}$. Our interpretation is corroborated by the apparent preferential preservation of lipid-rich cellular envelopes ${ }^{11}$ (Fig. 2o and Extended Data Fig. 2d), intracellular vacuoles ${ }^{17}$ (Fig. 2k) and extracellular lamellar membranes ${ }^{11}$ (Fig. 2n and Extended Data Fig. 2b).

Apart from hydrocarbons, traces of the original biomolecular makeup_including cholesterol derivatives (Fig. 4b and Extended Data Fig. 4a) and proteinaceous constituents (Fig. 4a and Extended Data Figs. 5a, b, 6) that retain the immunological characteristics of tropomyosin, haemoglobin, $\alpha$-keratin, elastin, actin and collagen (Fig. $4 \mathrm{e}-\mathrm{n}$ and Extended Data Fig. 7a-f) - were detected using a combination of ToF-SIMS, Py-GC/MS, amino acid analysis and in situ immunohistochemistry that incorporated both fluorescence and immunogold labelling. ToF-SIMS and immunohistochemistry further demonstrated co-localization of the geochemical signatures within discrete tissue regions (Fig. 4e-n and Extended Data Figs. 5a, b, 7a-f). Antibody reactivity showed that the various epitopes were spatially distinct, and thus comparable to immunolabelling patterns produced by artificially matured leatherback sea turtle and harbour porpoise (Phocoena phocoena) integuments (Extended Data Figs. 7i-t, 9n-q). Although remnant $\beta$-keratin has previously been reported from epidermal appendages of other Mesozoic vertebrates ${ }^{18}$, we were unable to recognize breakdown products of this durable ${ }^{19}$ protein (Extended Data Fig. $7 \mathrm{~g}, \mathrm{~h}$ ). $\beta$-keratin is responsible for the development of hard corneous layers in sauropsid claws, scales and scutes ${ }^{20}$. Therefore, the apparent absence of this protein in MH 432 supports our microscopy-based observation of a scaleless skin in this ichthyosaur.

\section{Blubber}

The subcutaneous layer of MH 432 is over $500 \mu \mathrm{m}$ thick, and comprises a glossy black material superimposed over a fibrous mat (Fig. 5a). 

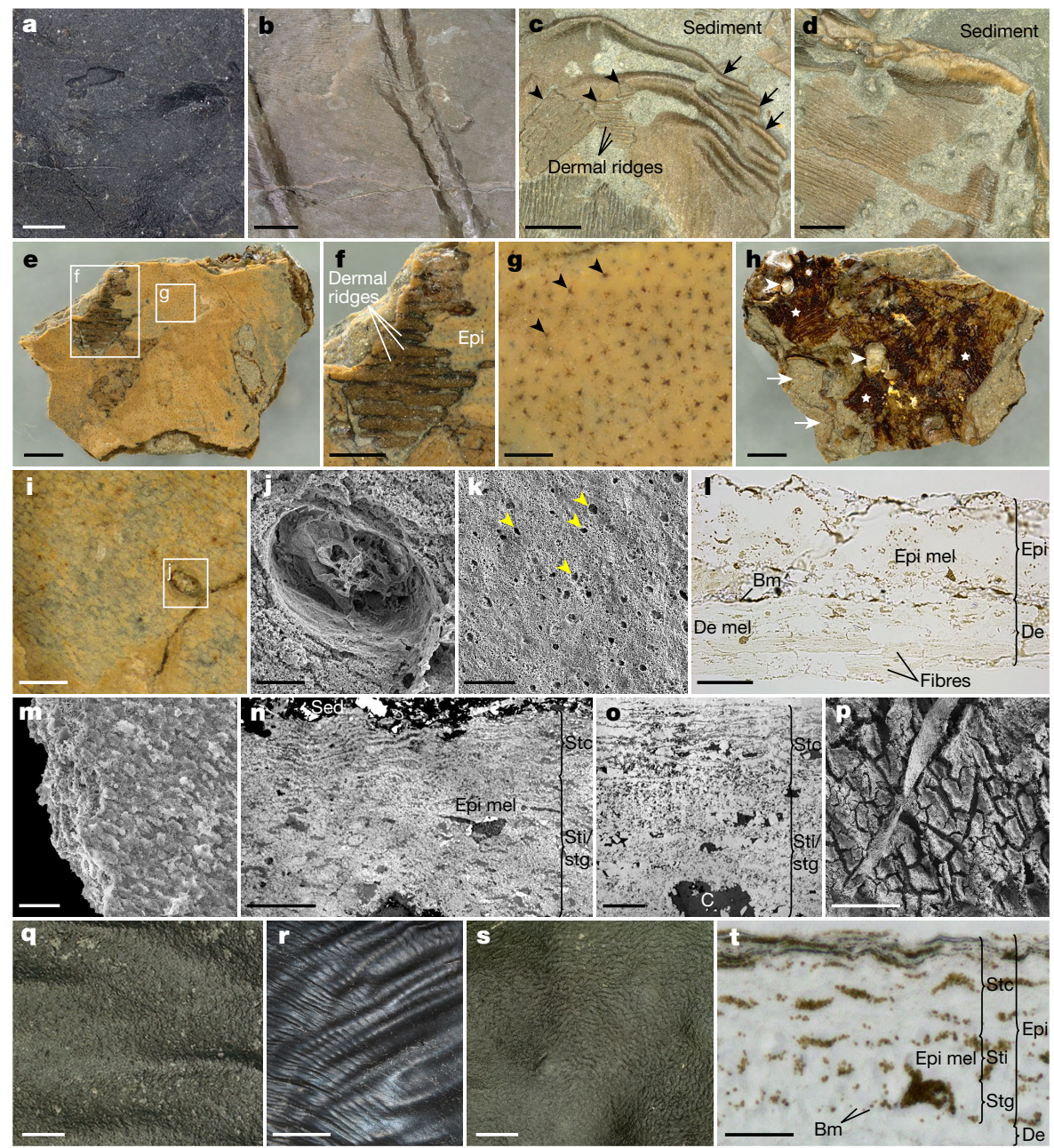

Fig. 2 | Fine structure of integument of Stenopterygius specimen MH 432. a, External aspect of untreated epidermis (sample 13) showing absence of scales (compare with $\mathbf{q}$ and $\mathbf{s}$ ). $\mathbf{b}$, Skin adhering to the gastralia. c, Folding (arrows) and fragmentation (arrowheads) of the integument (compare with $\mathbf{r}$ ). d, Trailing edge of the right pelvic fin with post mortem rippling. e, Exterior of demineralized flank integument (sample 13a). f, Enlargement of interdigitating epidermal and dermal ridges. Epi, epidermis. g, Magnified image of subsurface melanophores (arrowheads) embedded in the semi-transparent epidermis. h, Internal aspect of demineralized integument showing remnants of blubber and underlying connective tissue (stars). Arrows, infiltrating sediment; arrowheads, authigenic silica minerals. i, Demineralized belly skin surface (sample 10) that lacks epidermal melanophores (compare with $\mathbf{g}$ ). $\mathbf{j}$, Field emission gun scanning electron microscopy (FEG-SEM) micrograph of a potential pore. k, Fractured stratum corneum (sample 13a) with presumed lipid

Histological and chemical analysis showed vertical stratification into a dense, indistinctly laminated carbonaceous unit sandwiched between two sets of surface-parallel seams that are enriched in calcium phosphate (Fig. 5b-f, 1, m and Extended Data Fig. 5c). The dark matter is dominated by aliphatic and aromatic compounds (Fig. 5i-n), and appears to represent a highly condensed tissue residue in which geopolymers are so abundant that they obscure virtually all microstructural details when inspected under transmission electron microscopy (TEM) (Fig. 5e, f). This compares well with previously documented fossilized lipid-rich source structures ${ }^{14-16}$. Moreover, our artificial maturation of harbour porpoise integument (Extended Data Fig. $9 \mathrm{e}-\mathrm{q}$ ) demonstrates that blubber-the peripherally distributed fibro-adipose tissue layer that has only previously been identified in modern cetaceans, sirenians, pinnipeds and the leatherback sea turtle 21,22 - converts into a similarly condensed mass of flattened cells and fibre bundles when subjected to elevated pressure and inclusions preserved as cavities (arrowheads). 1, Light microscopy section through stratified skin (sample 12a) (compare with $\mathbf{t}$ ). Bm, basement membrane; de, dermis; de mel, dermal melanophore; epi mel, epidermal melanophore. $\mathbf{m}$, Oblique transverse section through the stratum corneum (sample 10). n, TEM section through pigmented epidermis (sample 13). Sed, sediment; stc, stratum corneum; sti/stg, stratum intermedium and/or stratum germinativum. o, TEM section through unpigmented epidermis (sample 10). C, cavity. p, FEG-SEM micrograph of dermal fibres in external view (sample 13). q, Delphinus delphis skin surface. r, Post mortem deformation of $D$. delphis skin. $\mathbf{s}$, Scaleless carapace skin of adult D. coriacea. $\mathbf{t}$, Light microscopy section through carapace skin of juvenile D. coriacea. Scale bars, $5 \mu \mathrm{m}(\mathbf{o}), 20 \mu \mathrm{m}(\mathbf{j}, \mathbf{n}, \mathbf{t}), 30 \mu \mathrm{m}(\mathbf{k}), 50 \mu \mathrm{m}(\mathbf{l}, \mathbf{m})$, $100 \mu \mathrm{m}(\mathbf{g}, \mathbf{i}), 200 \mu \mathrm{m}(\mathbf{p}), 300 \mu \mathrm{m}(\mathbf{f}), 500 \mu \mathrm{m}(\mathbf{a}, \mathbf{e}, \mathbf{h}, \mathbf{q}, \mathbf{s}), 1 \mathrm{~mm}(\mathbf{c}, \mathbf{d})$, $2 \mathrm{~mm}(\mathbf{b}), 1 \mathrm{~cm}(\mathbf{r})$.

temperature (the epidermis was otherwise relatively unaffected by these experimental procedures; Extended Data Fig. 9f-i). On the basis of the anatomical localization, chemical composition and fabric of the

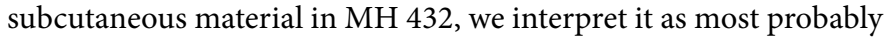
representing fossilized blubber. Support for this hypothesis includes the presence of potential fatty acid-derived moieties (Extended Data Fig. 4 b), as well as the calcium phosphate-reinforced seams (Fig. 5c, d, $1, \mathrm{~m}$ and Extended Data Fig. 5c) that correspond anatomically to the reticular dermis and superficial fascia of extant balaenid ${ }^{10}$ and odontocete ${ }^{9}$ whales. These connective tissue layers consist of closely spaced collagen and elastin strands that enclose the parts of the blubber that are more laden with fat. Although integumental fibrillar proteins do not normally biomineralize ${ }^{23}$, they do possess an inherent ability to bind calcium and phosphate ions ${ }^{24}$, and thus could feasibly have induced the nucleation of calcium phosphate nano-crystallites during the eogenesis of $\mathrm{MH} 432$. 


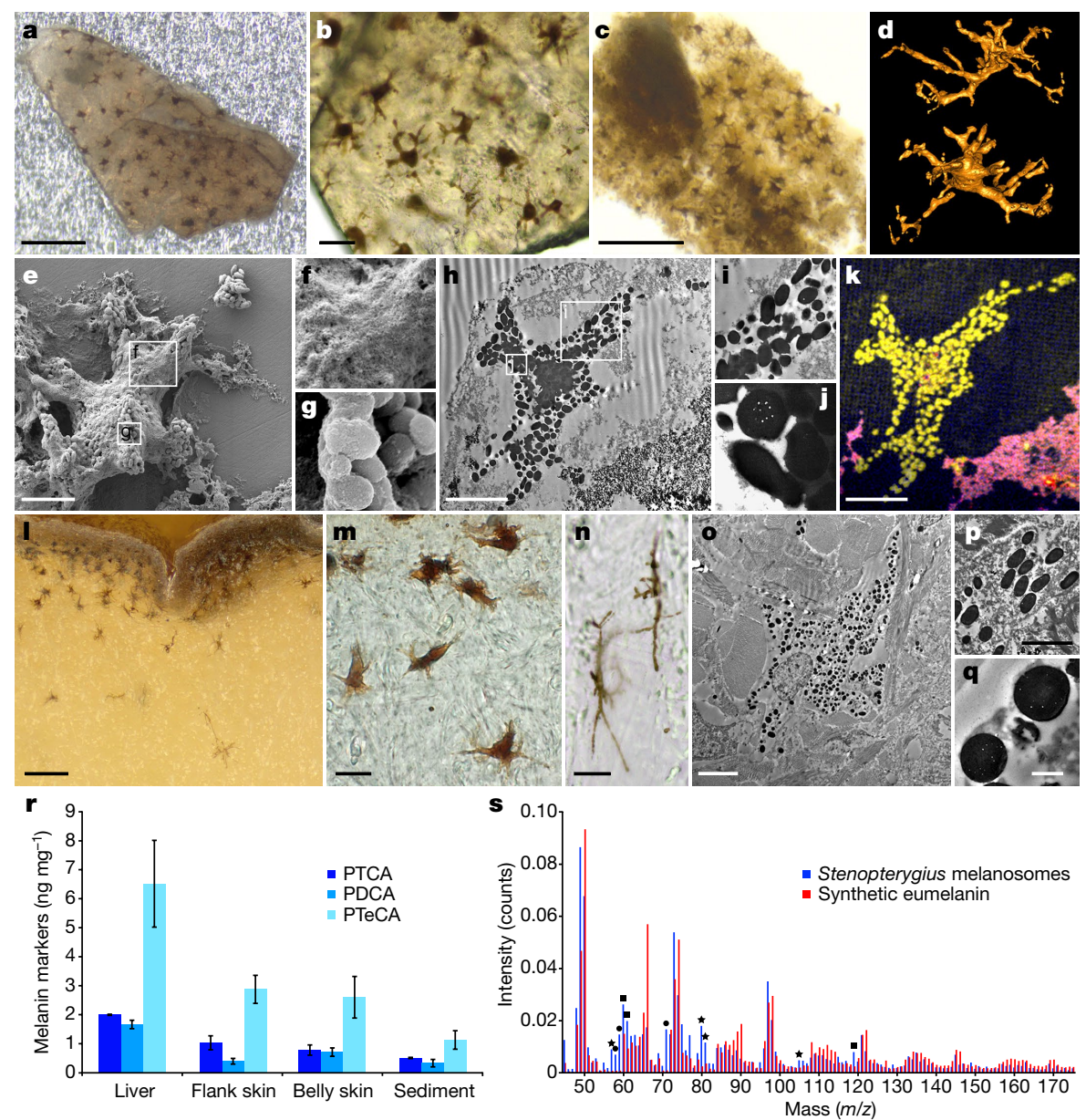

Fig. 3 Melanophores, melanosomes and eumelanin associated with MH 432. a, Light micrograph of epidermal melanophores embedded in semi-transparent phosphatic matrix (sample 13b). b, Enlargement of fossil pigment cells and their branching processes (compare with m). c, Melanophores retained in soft and pliable organic matter after demineralization (sample 13). d, Synchrotron-radiation X-ray tomographic microscopy (SRXTM) rendering of a melanophore with dendritic processes (sample 18). e, FEG-SEM micrograph of a melanophore liberated from demineralized skin (sample 13). f, Magnified outer membrane. g, Enlargement showing stacked melanosomes.

h, TEM micrograph of a branched melanophore that contains melanosome organelles surrounded by matrix (sample 13; compare with o).

i, Magnified cellular extension with dispersed melanosomes (compare with p). j, Enlargement showing internal melanosome vacuoles (compare with q). $\mathbf{k}$, False-colour negative ion NanoSIMS image illustrating the

Owing to taphonomic overprinting, the original thickness of the blubber in MH 432 is difficult to estimate. However, on the basis of comparisons with our experimental reduction of a 20-mm-thick blubber layer from a 1.24-m-long harbour porpoise to less than $250 \mu \mathrm{m}$ under artificially created diagenetic conditions (Extended Data Fig. 9e-j), the depth of the blubber in MH 432 must have been considerable.

\section{Implications}

Existing evidence indicates that ichthyosaurs were predominantly dark-coloured in life $\mathrm{e}^{2,3,25}$, similar to most air-breathing vertebrates that inhabit pelagic environments today ${ }^{8,26,27}$. More elaborate patterns involving multiple biochromes and/or photonic nanostructures have been proposed ${ }^{28}$, but are inconsistent with fossil data $a^{2,3,25}$, as well as the conservative skin palette found in extant oceanic amniotes ${ }^{8,27}$. Conversely, the conspicuous abundance of melanophores across the flank of MH 432 (Fig. 2g) contrasts with their absence in the belly region (Fig. 2i), which provides compelling evidence that this individual was originally countershaded. A distributional differentiation spatial distribution of $\mathrm{CH}^{-}$(blue), $\mathrm{CN}^{-}$(yellow) and $\mathrm{S}^{-}$(red) (see Extended Data Fig. 3e). 1-q, Melanophores in D. coriacea integument imaged under identical conditions as the ichthyosaur pigment cells. Flattened melanophores in $\mathbf{n}$ straddle a superficial blood vessel. $\mathbf{r}$, Quantification of eumelanin markers produced by chemical degradation of MH 432 samples 7a (liver), 13a, 13d (flank skin), 10a, 10b (belly skin) and 14a (sediment) (see Extended Data Fig. 3f). PTCA, pyrrole2,3,5-tricarboxylic acid; PDCA, pyrrole-2,3-dicarboxylic acid; PTeCA, pyrrole-2,3,4,5-tetracarboxylic acid. s, Negative ion ToF-SIMS spectra obtained from sectioned MH 432 melanosomes and synthetic eumelanin (see Supplementary Information). Fossil spectrum peaks that are not consistent with eumelanin represent inorganic ions (squares), epoxy (circles) and sulfur-containing organic ions (stars). Scale bars, $500 \mathrm{~nm}(\mathbf{q})$, $2 \mu \mathrm{m}(\mathbf{p}), 5 \mu \mathrm{m}(\mathbf{e}, \mathbf{h}, \mathbf{k}, \mathbf{o}), 20 \mu \mathrm{m}(\mathbf{b}, \mathbf{m}, \mathbf{n}), 100 \mu \mathrm{m}(\mathbf{a}, \mathbf{c}, \mathbf{l})$.

of dark and light melanin-based colours between the dorsal and ventral surfaces of the body occurs in many seagoing tetrapods ${ }^{8,27}$, and functions to provide camouflage ${ }^{29}$, protect against ultraviolet radiation during sea-surfacing behaviours ${ }^{30}$ and/or confer thermoregulatory advantages in cold climates ${ }^{31}$. Conflicting reports ${ }^{2,25}$ of monotonal schemes in smaller-bodied individuals of Stenopterygius might indicate ontogenetic changes in colour comparable to those seen in living sea turtles ${ }^{26}$. Moreover, our identification of branched melanophores hints at the possibility that ichthyosaurs were able to physiologically adjust their skin tone via redistribution of melanosomes ${ }^{12}$, perhaps to enable ultraviolet filtration, concealment or enhance body temperature stability.

Our morphological and chemical detection of blubber-a hallmark of warm-blooded marine amniotes ${ }^{21}$ - provides a rare window into the level of aquatic adaptation achieved by derived ichthyosaurs. In extant animals, blubber accentuates streamlining, buoyancy and serves as a fat store that can be metabolized during periods of energetic stress ${ }^{21,22}$. However, its primary role as an insulator is crucial to overcome the 

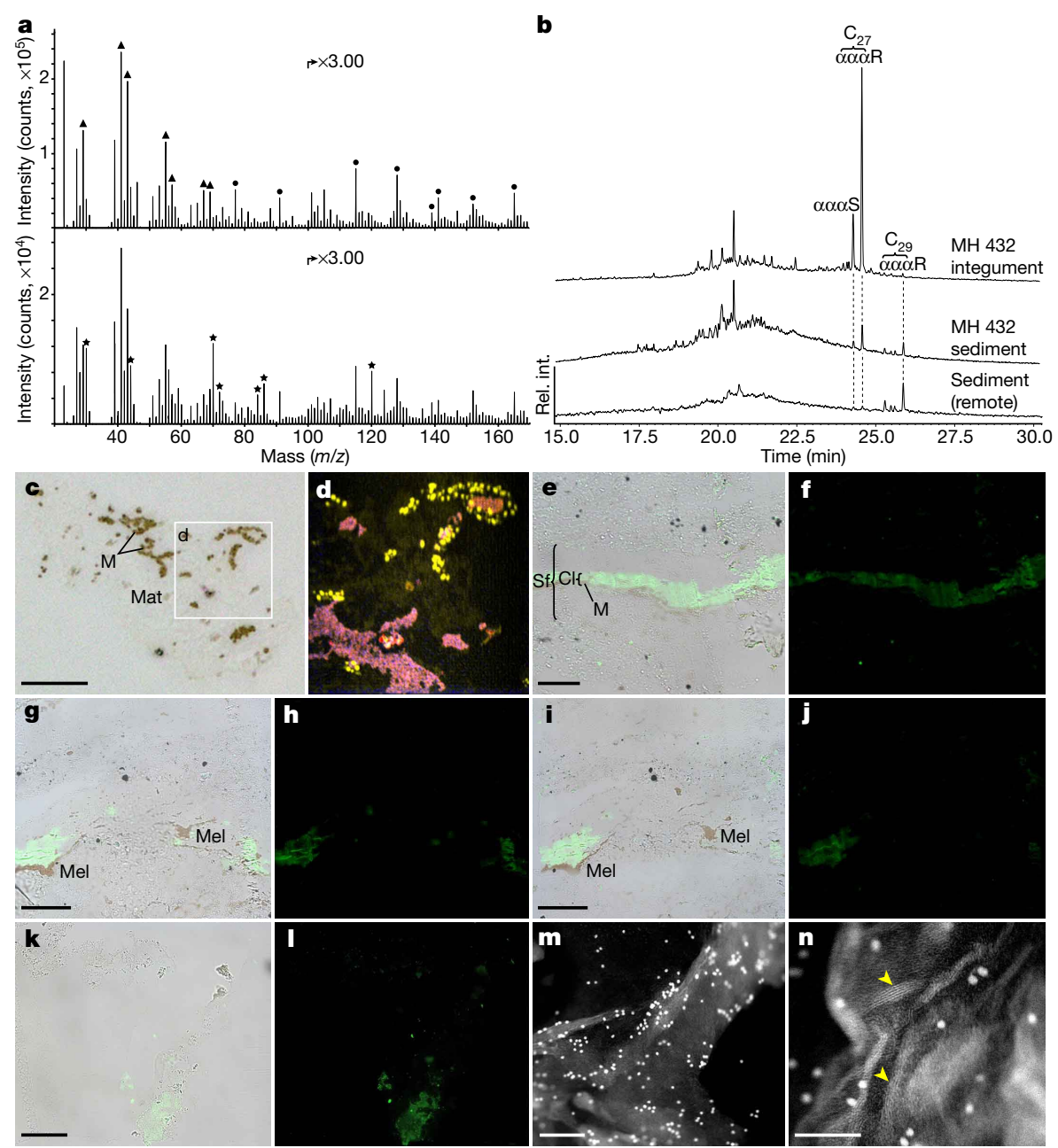

Fig. 4 | Chemistry of the skin of MH 432. a, Positive ion ToFSIMS spectra featuring peaks that are characteristic of aliphatic and polyaromatic hydrocarbons (top spectrum, triangles and circles; sample 2) and of proteinaceous compounds (bottom spectrum, stars; sample 13) (see Extended Data Fig. 5a, b). b, Py-GC/MS ion chromatograms $(m / z 217$, normalized to sample weight) that reveal eukaryote-derived steranes from the integument (sample 16), host rock (sample 14) and sediment sampled at a distance from the fossil (see Extended Data Fig. 4a). Cholestanes $\left(\mathrm{C}_{27}\right)$, present at high levels in the integument, are interpreted as diagenetic products of ichthyosaur cholesterol. Stigmastanes $\left(\mathrm{C}_{29}\right)$, which are present at pronounced levels in the sediment, represent background signal from algae and/or terrestrial plants. $\alpha \alpha \alpha \mathrm{S}$ and $\alpha \alpha \alpha \mathrm{R}$ represent (20S) $-5 \alpha, 14 \alpha, 17 \alpha(\mathrm{H})$ and $(20 \mathrm{R})-5 \alpha, 14 \alpha, 17 \alpha(\mathrm{H})$ isomers, respectively. Rel. int., relative intensity. c, d, Light microscopy section (c) and false-colour negative ion NanoSIMS image (d) illustrating the spatial distribution of $\mathrm{CH}^{-}$(blue), $\mathrm{CN}^{-}$(yellow) and $\mathrm{S}^{-}$(red) (see Extended Data
Fig. 2h). M, melanosomes; mat, skin matrix. e-1, Immunohistochemical staining of demineralized MH 432 skin material exposed to antisera raised against Gallus domesticus tropomyosin (sample 13) (e, f), Alligator mississippiensis haemoglobin (sample 13) (g, h), Struthio camelus haemoglobin (sample 13) (i, j) and G. domesticus $\alpha$-keratin (sample 8) $(\mathbf{k}, \mathbf{l})$. In $\mathbf{e}, \mathbf{g}, \mathbf{i}, \mathbf{k}$, the localization of antibody-antigen complexes is indicated via superimposed green fluorescent signal on transmitted light images of sectioned tissue; in $\mathbf{f}, \mathbf{h}, \mathbf{j}, \mathbf{l}$, a fluorescein isothiocyanate filter was used. Both anti-haemoglobin antibodies have a similar binding pattern, and are localized to a discrete structure (possibly a vessel) surrounded by a melanophore (compare with Fig. $3 \mathrm{n}$ ). Cl, concentration layer; mel, melanophore; sf, skin fold. m, n, Low-magnification (m) and high-magnification (n) immunogold labelling of MH 432 skin fibres exposed to anti- $\alpha$-keratin antibody (sample 12). Arrowheads, filamentous matter (compare with Extended Data Fig. 7s, t). Scale bars, $100 \mathrm{~nm}(\mathbf{n})$, $200 \mathrm{~nm}(\mathbf{m}), 20 \mu \mathrm{m}(\mathbf{c}), 30 \mu \mathrm{m}(\mathbf{e}, \mathbf{g}, \mathbf{i}, \mathbf{k})$. thermal conductivity of seawater ${ }^{21}$; the presence of this specialized fibro-adipose tissue layer in MH 432 is consistent with reconstructions of ichthyosaurs as homeotherms or regional endotherms ${ }^{4,32,33}$. Suggestions that these ancient reptiles were capable of mesopelagic deep-diving ${ }^{1}$, sustained cruising $^{1}$ and toleration of cold-water environments ${ }^{34}$ likewise accord with the development of blubber as one of many integrated physiological and behavioural mechanisms that are required to maintain a high body temperature that is independent of ambient conditions $s^{4,25,32,34}$.

Our experimental results demonstrate that the integument of Stenopterygius had both a smooth external surface and thick subcutaneous layer of fibro-adipose tissue. This is notably similar to modern whales ${ }^{9,10}$ and adult individuals of the leatherback sea turtle ${ }^{8}$, and reveals multiple aspects of soft-tissue convergence that range across a time span of more than 180 million years. In addition, the mosaic of cetacean and reptilian traits that is characteristic of Stenopterygius anatomy recurs in its integumental histology, with the presence of branched melanophores (rather than mammalian melanocytes) and absence of dermal ossifications (otherwise found in the leatherback sea turtle ${ }^{8}$ ). We attribute these adaptive specializations to the morphological and physiological constraints imposed upon all pelagic tetrapods during their evolutionary transition towards life in the sea.

\section{Online content}

Any methods, additional references, Nature Research reporting summaries, source data, statements of data availability and associated accession codes are available at https://doi.org/10.1038/s41586-018-0775-x.

Received: 18 March 2018; Accepted: 16 October 2018;

Published online 5 December 2018. 

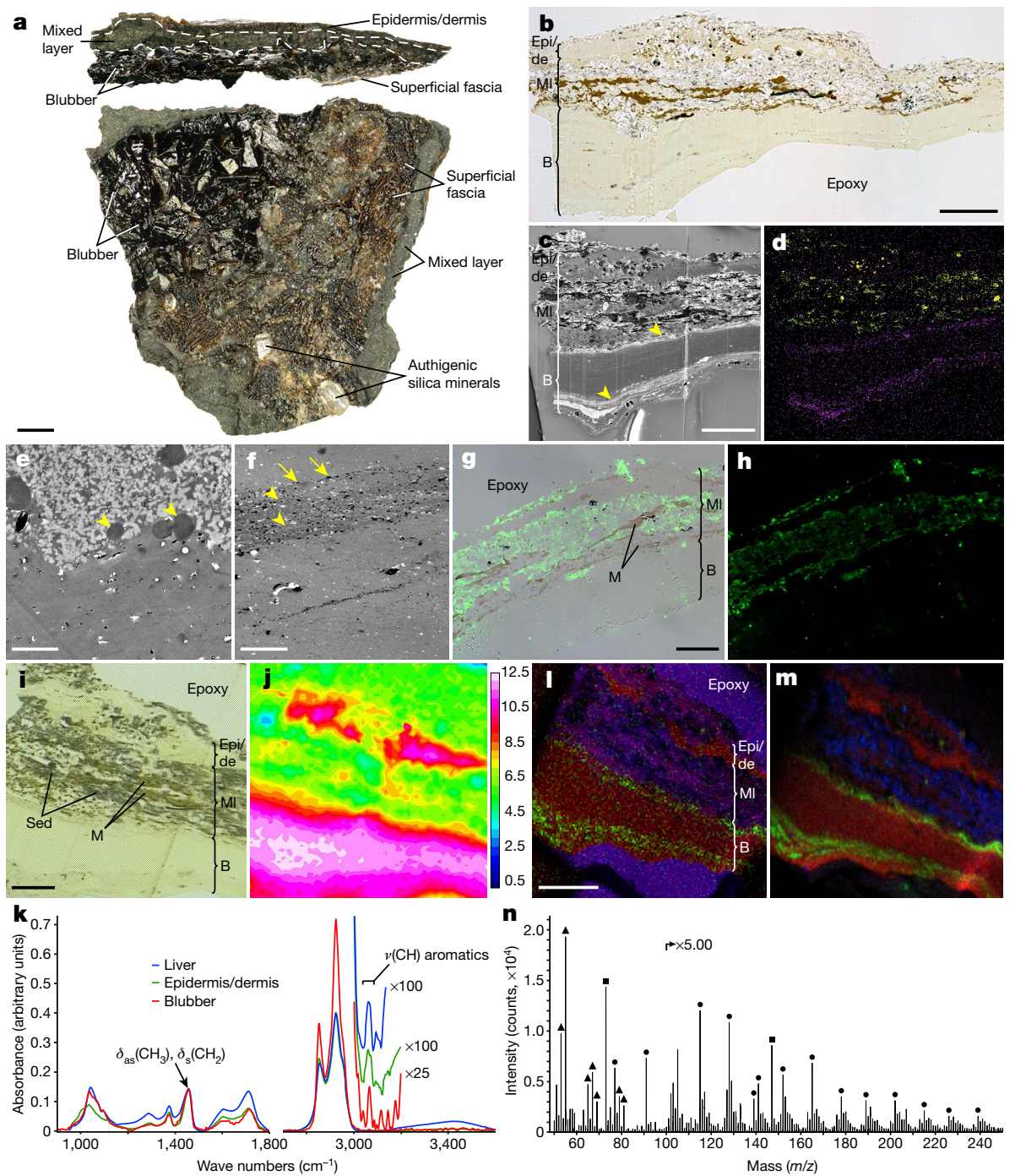

Fig. 5 Structure and chemistry of MH 432 blubber. a, Side (top) and internal (bottom) views of untreated integument (sample 13a). Dashed line demarcates a layer containing both endogenous (skin) and exogenous (clay and bacteria) features (see Extended Data Fig. 10d-h). b, Light microscopy section through demineralized integument (sample 13a). B, blubber; epi/de, epidermis and/or dermis; ml, mixed layer (see Supplementary Information). c, d, Back-scattered electron micrograph (c) and threecolour EDX map (d) (sample 13a) that indicate the distribution of aluminium (lime), phosphorous (purple) and sulfur (yellow). Arrowheads, reticular dermis (top) and superficial fascia (bottom). e, TEM micrograph from the interface between the phosphatized epidermis and/or dermis (top) and polymerized blubber (bottom). Arrowheads, scattered melanosomes. f, Organic seams (arrowheads) with calcium phosphate nano-crystallites (arrows) embedded in amorphous blubber residue. $\mathbf{g}, \mathbf{h}$, Immunohistochemical staining for antibodies raised against $\alpha$-keratin (green fluorescent signal) demonstrating absence of

1. Motani, R. Evolution of fish-shaped reptiles (Reptilia: Ichthyopterygia) in their physical environments and constraints. Annu. Rev. Earth Planet. Sci. 33, 395-420 (2005).

2. Fraas, E. Ueber die Finne von Ichthyosaurus. Jahresh. Vereins vaterl. Naturk. Württemberg 44, 280-303 (1888).

3. Whitear, M. On the colour of an ichthyosaur. Ann. Mag. Nat. Hist. 9, 742-744 (1956).

4. Wiman, C. Über Ichthyosaurier und Wale. Senckenbergiana 27, 1-11 (1946).

5. Lingham-Soliar, T. Rare soft tissue preservation showing fibrous structures in an ichthyosaur from the Lower Lias (Jurassic) of England. Proc. R. Soc. Lond. B 266, 2367-2373 (1999).

6. Martill, D. M. Prokaryote mats replacing soft tissues in Mesozoic marine reptiles. Mod. Geol. 11, 265-269 (1987).

7. Smithwick, F. M., Mayr, G., Saitta, E. T., Benton, M. J. \& Vinther, J. On the purported presence of fossilized collagen fibres in an ichthyosaur and a theropod dinosaur. Palaeontology 60, 409-422 (2017).

antibody-antigen complexes in the blubber (sample 13a). M, melanosomes. $\mathbf{i}-\mathbf{k}$, Infrared absorbance data from the blubber (sample 13a) along with spectra obtained from the epidermis and/or dermis (sample 13a) and liver (sample 1). Band assignments and vibration modes (as, asymmetric; $\delta$, deformation; s, symmetric; $\nu$, stretching) are shown in $\mathbf{k}$. Intensities in $\mathbf{j}$ originate from the $2,805-3,016-\mathrm{cm}^{-1}$ interval denoting $\nu(\mathrm{CH})$ absorption (see Supplementary Information). Sed, sediment (clay). l, Positive ion ToF-SIMS image of sample 13a showing the spatial distribution of peaks typical of polyaromatics (red), calcium phosphate (green) and epoxy (blue). m, Negative ion ToF-SIMS image with peaks characteristic of sulfur-containing fragments (red), phosphate (green) and silica (blue). n, Positive ion ToF-SIMS spectrum recorded from the blubber. Triangles and circles denote peaks typical of aliphatics and polyaromatics, respectively; squares, polydimethylsiloxane (see Supplementary Information). Scale bars, $1 \mu \mathrm{m}$ (e), $5 \mu \mathrm{m}(\mathbf{f}), 30 \mu \mathrm{m}$ (g, i), $50 \mu \mathrm{m}(\mathbf{b}, \mathbf{c}, \mathbf{l}), 500 \mu \mathrm{m}(\mathbf{a})$.

8. Wyneken, J. in The Leatherback Turtle: Biology and Conservation (eds Spotila, J. R. \& Tomillo, P. S.) 32-48 (John Hopkins Univ. Press, Baltimore, 2015).

9. Cozzi, B., Huggenberger, S. \& Oelschläger, H. Anatomy of Dolphins: Insights into Body Structure and Function (Academic, Amsterdam, 2017).

10. Reeb, D., Best, P. B. \& Kidson, S. H. Structure of the integument of southern right whales, Eubalaena australis. Anat. Rec. 290, 596-613 (2007).

11. Landmann, L. in Biology of the Integument (eds Bereiter-Hahn, J. et al.) 150-187 (Springer, Berlin, 1986).

12. Alibardi, L. Ultrastructural features of skin pigmentation in the lizard Heloderma suspectum with emphasis on xanto-melanophores. Acta Zool. 96, 154-159 (2015).

13. Wilby, P. R. \& Briggs, D. E. G. Taxonomic trends in the resolution of detail preserved in fossil phosphatized soft tissues. Geobios 30, 493-502 (1997).

14. Gupta, N. S., Tetlie, O. E., Briggs, D. E. G. \& Pancost, R. D. The fossilization of eurypterids: a result of molecular transformation. Palaios 22, 439-447 (2007). 
15. Gupta, N. S., Cody, G. D., Tetlie, O. E., Briggs, D. E. G. \& Summons, R. E. Rapid incorporation of lipids into macromolecules during experimental decay of invertebrates: initiation of geopolymer formation. Org. Geochem. 40, 589-594 (2009).

16. O'Reilly, S., Summons, R., Mayr, G. \& Vinther, J. Preservation of uropygial gland lipids in a 48-million-year-old bird. Proc. R. Soc. Lond. B 284, 20171050 (2017).

17. Jackson, M. K. \& Sharawy, M. Lipids and cholesterol clefts in the lacunar cells of snake skin. Anat. Rec. 190, 41-45 (1978).

18. Pan, Y. et al. Molecular evidence of keratin and melanosomes in feathers of the Early Cretaceous bird Eoconfuciusornis. Proc. Natl Acad. Sci. USA 113, E7900-E7907 (2016).

19. Moyer, A. E., Zheng, W. \& Schweitzer, M. H. Keratin durability has implications for the fossil record: results from a 10 year feather degradation experiment. PLOS ONE 11, e0157699 (2016).

20. Toni, M. \& Alibardi, L. Soft epidermis of a scaleless snake lacks beta-keratin. Eur. J. Histochem. 51, 145-151 (2007).

21. Iverson, S. J. in Encyclopedia of Marine Mammals (eds Perrin, W. F. et al.) 115-120 (Academic, Amsterdam, 2009).

22. Davenport, J. et al. Fat head: an analysis of head and neck insulation in the leatherback turtle (Dermochelys coriacea). J. Exp. Biol. 212, 2753-2759 (2009).

23. Fartasch, M., Haneke, E. \& Hornstein, O. P. Mineralization of collagen and elastic fibers in superficial dystrophic cutaneous calcification: an ultrastructural study. Dermatologica 181, 187-192 (1990).

24. Balakrishnan, S. et al. Studies on calcification efficacy of stingray fish skin collagen for possible use as scaffold for bone regeneration. Tissue Eng. Regen. Med. 12, 98-106 (2015).

25 . Lindgren, J. et al. Skin pigmentation provides evidence of convergent melanism in extinct marine reptiles. Nature 506, 484-488 (2014).

26. Wyneken, J. The Anatomy of Sea Turtles (U.S. Department of Commerce NOAA Technical Memorandum NMFS-SEFSC-470, 2001).

27. Shirihai, H. \& Jarrett, B. Whales, Dolphins, and Other Marine Mammals of the World (Princeton Univ. Press, Princeton, 2006).

28. Vinther, J. A guide to the field of palaeo colour: melanin and other pigments can fossilise: reconstructing colour patterns from ancient organisms can give new insights to ecology and behaviour. BioEssays 37, 643-656 (2015).

29. Marshall, J. \& Johnsen, S. in Animal Camouflage: Mechanisms and Function (eds Stevens, M. \& Merilaita, S.) 186-211 (Cambridge Univ. Press, Cambridge, 2011).

30. Martinez-Levasseur, L. M. et al. Acute sun damage and photoprotective responses in whales. Proc. R. Soc. Lond. B 278, 1581-1586 (2011)

31. James, M. C., Myers, R. A. \& Ottensmeyer, C. A. Behaviour of leatherback sea turtles, Dermochelys coriacea, during the migratory cycle. Proc. R. Soc. Lond. B 272, 1547-1555 (2005)

32. Bernard, A. et al. Regulation of body temperature by some Mesozoic marine reptiles. Science 328, 1379-1382 (2010)

33. Nakajima, Y., Houssaye, A. \& Endo, H. Osteohistology of the Early Triassic ichthyopterygian reptile Utatsusaurus hataii: implications for early ichthyosaur biology. Acta Palaeontol. Pol. 59, 343-352 (2014).
34. Kear, B. P. Marine reptiles from the Lower Cretaceous of South Australia: elements of a high-latitude cold-water assemblage. Palaeontology 49, 837-856 (2006).

Acknowledgements We thank E. R. Schroeter for scientific advice. S. M. Webb and C. Roach assisted during the SRS-XRF analysis. T. Wigren produced the artistic reconstructions. Financial support was provided by a Grant for Distinguished Young Researchers (642-2014-3773, Swedish Research Council) to J.L., as well as a National Science Foundation INSPIRE grant (EAR-1344198) to M.H.S. and W.Z., and donations from F. M. and S. P. Orr, and V. and G. Mullis. The Paul Scherrer Institute, Switzerland, provided beamtime at the TOMCAT beamline of the Swiss Light Source. SRS-XRF data were collected at the Stanford Synchrotron Radiation Lightsource using beamline 10-2. NanoSIMS measurements were obtained at the Chemical Imaging Infrastructure, Chalmers University of Technology and University of Gothenburg, which is supported by the Knut and Alice Wallenberg Foundation. Part of this work was performed at the Analytical Instrumentation Facility (AIF) of North Carolina State University. The AIF is supported by the State of North Carolina and the National Science Foundation (ECCS-1542015) and is a member of the North Carolina Research Triangle Nanotechnology Network, a site within the National Nanotechnology Coordinated Infrastructure.

Reviewer information Nature thanks A. Houssaye, B. Kessler, S. Kiel and R. N. S. Sodhi for their contribution to the peer review of this work.

Author contributions J.L. conceived the project. The text was written by J.L. and B.P.K. with contributions from S.S., P.S., M.H.S. and P.E.A., and feedback from all authors. All figures were assembled by J.L. with input from all authors R.H. collected and prepared MH 432. J.L., P.S. and M.J. recorded the SRS-XRF measurements; O.G., P.S., C.A., T.K. and J.L. conducted the FEG-SEM and TEM analyses; V.T. performed the Py-GC/MS experiments; S.I. and K.W. carried out the alkaline hydrogen peroxide oxidation analysis; M.H.S. and W.Z. conducted the immunohistochemistry investigation; P.S. and J.L. performed the ToF-SIMS experiments; A.T., P.M., J.L. and P.S. carried out the NanoSIMS analysis; A.E., J.L. and P.U. recorded the infrared microspectroscopic measurements; M.E.E. and F.M. acquired the SRXTM data; M.O. performed the amino acid analysis; and M.J. and I.R.-M. conducted the maturation experiments.

Competing interests The authors declare no competing interests.

Additional information

Extended data is available for this paper at https://doi.org/10.1038/s41586018-0775-x.

Supplementary information is available for this paper at https://doi.org/ 10.1038/s41586-018-0775-x.

Reprints and permissions information is available at http://www.nature.com/ reprints.

Correspondence and requests for materials should be addressed to J.L.

Publisher's note: Springer Nature remains neutral with regard to jurisdictional claims in published maps and institutional affiliations. 


\section{METHODS}

Fossil material. Before analysis, MH 432 was rinsed multiple times with $96 \%$ ethanol and Milli-Q water to remove potential contaminants from human handling. Tissue and sediment samples were collected from the fossil using sterile instruments and washed successively in $96 \%$ ethanol and Milli-Q water. They were subsequently dried under a hood, wrapped loosely in aluminium foil, and stored in sealed, sterile containers. Samples selected for light microscopy, FEG-SEM, TEM, NanoSIMS, ToF-SIMS and infrared microspectroscopy were demineralized using EDTA (0.5 M, pH 8.0) for about four weeks with regular buffer changes to dissolve the mineral phase. Debris from the demineralization process was rinsed multiple times with Milli-Q water to discard remaining EDTA. Fresh aluminium foil was used to cover all work areas, and surgical gloves were worn during all handling and treatment. Experimental parameters between ancient and modern (see below) materials were identical; however, both sets of samples were treated in segregated laboratory spaces.

Modern reference materials. Frozen tissue samples from a sub-adult male harbour porpoise, P. phocoena (A2016/05526), found dead in Swedish waters in 2016, were provided by the Department of Environmental Research and Monitoring, Environmental Specimen Bank, Swedish Museum of Natural History, Stockholm. Similarly, integumental samples from a juvenile male short-beaked common dolphin, D. delphis (SAM M26880), washed up dead in South Australia in 2012, were obtained from the South Australian Museum (SAM), Adelaide. A juvenile leatherback sea turtle, D. coriacea (ZMUC-R2106), stored in 70\% ethanol, was acquired as a gift from Danmarks Akvarium in 1962, and has since been part of the vertebrate collection at the Zoological Museum, Natural History Museum of Denmark (ZMUC), Copenhagen. The beached carcass of a second (adult female) D. coriacea (ZMUC-R2112) was recovered in Denmark in 1979. The integument from ZMUC-R2112 was cleaned and dried, and is currently housed in the collections at the ZMUC.

Maturation experiments. Integument samples from the juvenile leatherback sea turtle (Extended Data Fig. 9a) and harbour porpoise (Extended Data Fig. 9e) were placed in cylindrical borosilicate glass vials with the epidermis facing downwards. The samples were then pressed from the hypodermis side using glass rods with flattened ends that were inserted into the vials. Each vial was placed in a larger beaker, and another smaller beaker (containing $600 \mathrm{~g}$ sand) was placed on top of the glass rod to compact the integument. The whole apparatus was placed in a ventilated oven heated to $80^{\circ} \mathrm{C}$. The samples were inspected at regular intervals (after $4 \mathrm{~h}$ on the first day, and then once on each following day), and the colourless oil expelled from the porpoise blubber was removed using a glass pipette. The samples were heated in this same manner for six consecutive days, during which the fatty inner tissues were compressed into a brittle amber-coloured substance (the epidermis was otherwise only slightly transformed by this same treatment; Extended Data Fig. 9f, g).

To artificially accelerate the maturation process, we also exposed the samples to higher temperatures and pressures. Each compacted sample was first cut into four smaller sections, with one wrapped in aluminium foil and then placed in an autoclave. The autoclave consisted of a stainless-steel high-pressure vessel $(30 \times 10$-mm column, Applied Porous Technologies) connected to an argon gas cylinder. The autoclave was purged three times by filling it to 80 bar with argon gas, before being relieved through the exhaust pipe. The autoclave was subsequently filled to approximately $75 \%$ of the desired final pressure, and heated in a thermostat-controlled oven (GC oven, 5890 series II, Hewlett Packard). After a few minutes (when the system had reached the desired temperature), a manual valve was used to adjust the final pressure to $200 \mathrm{bar}$. The samples were first exposed to $100^{\circ} \mathrm{C}$ and $200 \mathrm{bar}$ for $24 \mathrm{~h}$, and then to $150^{\circ} \mathrm{C}$ and $200 \mathrm{bar}$ for $96 \mathrm{~h}$; this second exposure was necessary because no further morphological changes were apparent after treatment at $100^{\circ} \mathrm{C}$ and $200 \mathrm{bar}$. These procedures were found to darken the porpoise blubber (Extended Data Fig. 9h). Sample sections exposed to $200^{\circ} \mathrm{C}$ and $200 \mathrm{bar}$ for $24 \mathrm{~h}$ either disintegrated completely or turned into a sticky semi-solid substance, which was not examined further.

Light microscopy. Tissue samples from our comparative selection of extant animals were inundated in freshly prepared fixative solution, $2 \%$ paraformaldehyde and $2.5 \%$ glutaraldehyde in $0.1 \mathrm{M}$ cacodylate buffer $(\mathrm{pH} 7.4)$ for $24 \mathrm{~h}$ at $4{ }^{\circ} \mathrm{C}$. The samples were then dehydrated in a graded ethanol series and embedded in epoxy resin (Agar 100, Resin kit R1031) via acetone, which was left to polymerize for 48 $\mathrm{h}$ at $60^{\circ} \mathrm{C}$. The demineralized fossil tissue was immersed in epoxy resin (AGAR 100 , resin kit R1031), which was left to polymerize at room temperature for $72 \mathrm{~h}$, followed by $48 \mathrm{~h}$ at $60^{\circ} \mathrm{C}$. Semi-thin $(1.5-\mu \mathrm{m})$ light-microscopic sections were then cut with a glass knife using a Leica EM UC7 Ultramicrotome, and mounted on objective glasses. Every second section was stained with Richardson's solution, before examination using an Olympus CX21 microscope. Micrographs were recorded using a Lumenera Infinity 2-1RC CCD camera with Lumenera Infinity Analyze version 6.4.1 software.

FEG-SEM and EDX. Untreated and demineralized fossil samples were mounted on conductive tape, sterile silicon wafers or $\mathrm{CaF}_{2}$ infrared windows. Following
ToF-SIMS and/or infrared microspectroscopic measurements (see below), the samples were coated with gold or platinum/palladium using a Cressington 208HR High Resolution Sputter Coater. They were then studied in a Tescan Mira3 High Resolution Schottky FEG-SEM with both standard and in-lens secondary electron and back-scattered electron detectors at acceleration voltages between 1 and 15 $\mathrm{kV}$, and a working distance of 3-10 $\mathrm{mm}$. Elemental analyses and mappings were performed with an energy-dispersive spectrometer (X-MaxN 80, $124 \mathrm{eV}, 80 \mathrm{~mm}^{2}$ ) from Oxford Instruments, linked to the instrument. Additional investigations were conducted on gold/palladium-coated samples in a Zeiss Supra 40VP FEG-SEM ( $2 \mathrm{keV}$ electron energy, 3-5 mm working distance, Everhart-Thornley secondary electron detector).

TEM. Tissue samples from our comparative selection of extant animals were fixed and embedded in epoxy resin as described in 'Light microscopy'. Ultra-thin (50$\mathrm{nm}$ ) sections were cut using a Leica EM UC7 Ultramicrotome equipped with a diamond knife, and mounted on pioloform-coated copper grids without further treatment or staining. Demineralized fossil tissue was likewise embedded in epoxy resin (see 'Light microscopy'). Ultra-thin (50-nm) sections were cut and mounted on copper grids without further treatment or staining. All sections were examined in a JEOL JEM-1400 PLUS TEM at $100 \mathrm{kV}$. Micrographs were recorded with a JEOL Matataki CMOS camera using TEM Centre for JEM1400 Plus software.

In situ immunohistochemistry. Extant animal and demineralized fossil tissues were embedded in LR White (hard grade, EMS, Cat\# 14383) according to the manufacturer's specifications. Sections ( $200 \mathrm{~nm}$ thick) were taken on a Leica EM UC6 Ultramicrotome for in situ immunohistochemistry, whereas 90-nm sections were used for post-embedding TEM immunogold labelling. The 200-nm sections were transferred to 6-well Teflon-coated slides and dried before being etched with $25 \mu \mathrm{g} / \mathrm{ml}$ proteinase $\mathrm{K}$ and $0.5 \mathrm{M}$ EDTA for epitope retrieval. This was followed by incubation in $1 \mathrm{mg} / \mathrm{ml}$ sodium borohydride to quench autofluorescence. Nonspecific binding was prevented by incubating sections in $4 \%$ normal serum before immune labelling with each primary antibody overnight at $4{ }^{\circ} \mathrm{C}$; working dilutions followed specifications recommended by the manufacturers. After repeated washing to remove unbound antibodies, the sections were incubated with a biotinconjugated secondary antibody for $2 \mathrm{~h}$ at room temperature. An avidin-biotin reagent (Vector Laboratories A-2001) was applied for $1 \mathrm{~h}$. All incubations were separated by sequential washes using $1 \times$ PBS. Finally, all sections were mounted with anti-fade mounting medium (Vector H-1000), and coverslips were applied. Examinations were undertaken using a Zeiss Axioskop 2 Plus biological microscope.

Immunogold assays were performed at room temperature on both the extant and fossil tissue samples. The fossil tissues were prepared in a specifically designed laboratory in which no modern animal tissues are permitted; conversely, the extant-animal samples were prepared in a separate laboratory. Sections of $90-\mathrm{nm}$ thickness were collected on carbon-coated nickel grids (EMS, Cat\# CFT200-NI). The grids were then incubated in: (1) PBS buffer with $1 \%$ Tween 20 for $10 \mathrm{~min}$; (2) $4 \%$ donkey serum in PBS ( $1 \mathrm{~h})$; (3) primary antibodies against $\alpha$-keratin (1:10) for $3 \mathrm{~h}$; (4) washed with PBS buffer with 1\% Tween20 10 times; and (5) $18 \mathrm{~nm}$ Colloidal Gold AffiniPure donkey anti-goat IgG $(\mathrm{H}+\mathrm{L})$ 1:10 (Jackson Immuno Research, Cat\# 705-215-147). After incubation with primary antibodies, the grids were washed using the procedures outlined above, and then stained in methanolic uranyl acetate followed by Reynold's lead citrate, and inspected using an aberration-corrected STEM-FEI Titan 80-300 electron microscope.

SRXTM. SRXTM was performed at the TOMCAT beamline of the Swiss Light Source, Paul Scherrer Institute, Switzerland. Samples were mounted on either low-light-refractive, 0.3-mm fishing lines (Berkley, Trilene super strong, 100\% fluorocarbon) or wooden toothpicks. The beam energy was set to $12 \mathrm{or} 20 \mathrm{keV}$, depending on sample size. The transmitted $\mathrm{X}$-rays were converted into visible light by a $5.9-\mu \mathrm{m}$-thick Tb-doped LSO scintillator screen (FEE). Projection images $\left(1,200\right.$ over $\left.180^{\circ}\right)$ were magnified by microscope optics $(40 \times)$, and digitized by a sCMOS camera (PCO.edge 5.5 ) with a $2,560 \times 2,160$ pixel chip, a $6.5-\mu \mathrm{m}$ pitch, and a 16-bit dynamic range. Tomographic reconstructions followed single-distance phase retrieval of the acquired projections, and were performed using a Fourier transform method routine, and a gridding procedure. The resulting tomographic volumes had an isotropic voxel size of $0.16 \mu \mathrm{m}$, and were rendered using Voxler 2 and 3.

SRS-XRF. X-ray fluorescence images were collected at the Stanford Synchrotron Radiation Lightsource using beamline 10-2. The incident X-ray energy was set to $11.0 \mathrm{keV}$ using a $\mathrm{Si}$ (111) double-crystal monochromator with the Stanford Positron Electron Accelerating Ring storage ring containing $500 \mathrm{~mA}$ at $3.0 \mathrm{GeV}$. The fluorescence lines of the targeted elements, as well as the intensity of the total scattered X-rays, were monitored using a silicon drift Vortex detector (SII NanoTechnology). The focused beam of $100 \times 100 \mu \mathrm{m}$ was determined by a $100-$ $\mu \mathrm{m}$ Ta pinhole aperture. The incident and transmitted X-ray intensities were measured with nitrogen-filled ion chambers, and the incident X-ray flux on the sample was measured at $\sim 8 \times 10^{10} \mathrm{ph} / \mathrm{s}$. The samples were mounted at $45^{\circ}$ relative to the incident X-ray beam, with the fluorescence detector mounted at $90^{\circ}$ relative to 
the incident beam. The sample and detector were maintained within an ambient atmospheric environment, with the detector held at a distance of $\sim 4 \mathrm{~cm}$ from the sample. The samples were mounted vertically on an aluminium bracket, and spatially rastered in the X-ray beam while data were collected continuously during stage motion. The fluorescence signal was gated by the encoder signal at pixel sizes of 100 or $200 \mu \mathrm{m}$. Beam exposure time was $20 \mathrm{~ms}$ per pixel.

Infrared microspectroscopy. Infrared microspectroscopic measurements were recorded at the Department of Biology, Lund University. A Hyperion 3000 microscope combined with a Tensor 27 spectrometer was used, together with either a single element mercury cadmium telluride $(\mathrm{MCT})$ detector $(250 \times 250 \mu \mathrm{m})$, or a $64 \times 64$ pixel focal plane array (FPA) detector and a Globar light source. The microscope was operated in transmission mode at $4 \mathrm{~cm}^{-1}$ resolution, and a $15 \times$ objective was used. One hundred and twenty-eight individual scans were averaged to achieve a good signal-to-noise ratio. Sample 13 (which includes the isolated melanophore depicted in Fig. 3e-g and Extended Data Fig. 3d, g) was also analysed at the SMIS beamline, Synchrotron SOLEIL, France. This facility uses an Agilent Cary 620 FTIR microscope system with a $128 \times 128$ FPA MCT detector $\left(4-\mathrm{cm}^{-1}\right.$ resolution, $25 \times$ objective).

NanoSIMS. Ion images were acquired using the Cameca NanoSIMS 50L instrument at the Chemical Imaging Infrastructure, Chalmers University of Technology and University of Gothenburg. Measurements were performed with a $16 \mathrm{keV} \mathrm{Cs}^{+}$ primary ion beam, rastering the sample surface using a $1.5 \mathrm{pA}$ (aperture diaphragm D1 2) primary current. The spatial resolution of the primary beam size was $200 \mathrm{~nm}$. The count rates of the ${ }^{12} \mathrm{C}^{1} \mathrm{H}^{-},{ }^{12} \mathrm{C}^{14} \mathrm{~N}^{-},{ }^{28} \mathrm{Si}^{-},{ }^{31} \mathrm{P}^{-},{ }^{32} \mathrm{~S}^{-}$and ${ }^{40} \mathrm{Ca}^{16} \mathrm{O}^{-}$were measured simultaneously in multicollection mode using electron multipliers. Mass-filtered images were then acquired using entrance slit 3 (width, $20 \mu \mathrm{m}$ ) and aperture slit 2 (width, $200 \mu \mathrm{m}$ ); the energy slit was kept fully open (energy band pass, $\leq 100 \mathrm{eV}$ ). The relative transmission of the mass spectrometer is $\sim 38 \%$ with a mass resolving power of 9,000 on ${ }^{28} \mathrm{Si}^{-}$(CAMECA definition). Each image is composed of 10 planes (for each measured mass). Images were processed using ImageJ and the OpenMIMS plugin. The count rates were corrected using a dead time of $44 \mathrm{~ns}$ for each electron multiplier.

ToF-SIMS. ToF-SIMS analyses were conducted in the static SIMS mode on a TOFSIMS IV instrument (IONTOF GmbH) using $25 \mathrm{keV} \mathrm{Bi}_{3}{ }^{+}$primary ions and low-energy electron flooding for charge compensation. Positive and negative ion data were acquired with the instrument optimized for either high mass-resolution $(\mathrm{m} / \Delta m \sim 5,000$, spatial resolution $\sim 3-4 \mu \mathrm{m})$ or high image-resolution $(\mathrm{m} / \Delta \mathrm{m}$ $\sim 300$, spatial resolution $\sim 0.2-0.5 \mu \mathrm{m}$ ), because these properties cannot be optimized simultaneously without inordinate increases in analysis time ${ }^{35}$. The pulsed primary ion current was set at $0.10 \mathrm{pA}$ for the high mass-resolution data, and $0.04 \mathrm{pA}$ for the high image-resolution data.

Py-GC/MS. Untreated fossil and sediment samples were ground to powder and loaded on a fast-heating Pt-filament of a Pyrola 2000 device (Pyrolab SB) coupled to a Varian CP3800 GC and a Varian 1200L MS. Two GC/MS runs were conducted on each sample. First, the filament was heated in $2 \mathrm{~ms}$ from 200 to $330^{\circ} \mathrm{C}$ (hold $40 \mathrm{~s}$ ), and a GC/MS run was performed to record the resulting volatile bitumen compounds and contaminants (if present). The sample remained in the pyrolysis device throughout the duration of this first run. In the second run, the temperature was increased to $560^{\circ} \mathrm{C}$ (hold $10 \mathrm{~s}$ ) within $2 \mathrm{~ms}$ to release compounds and moieties that were tightly bound to the organic matter (runs shown in Fig. $4 \mathrm{~b}$ and Extended Data Fig. 4). Samples were weighed onto the pyrolysis filament ( $\sim 5 \mathrm{mg}$ for each run). As a monitor of system performance, $40 \mathrm{ng}$ of perdeuterated $n$-icosane $\left(\mathrm{C}_{20} \mathrm{D}_{42}\right.$; Sigma) dissolved in $4 \mu \mathrm{l} n$-hexane was added to each sample. Here, we show pyrograms that exhibited high transfer efficiency consistent with the standard (Fig. 4 b and Extended Data Fig. 4). Chromatograms were normalized to the sample weight loaded onto the pyrolysis filament (Fig. $4 \mathrm{~b}$ and Extended Data Fig. $4 \mathrm{~b}$ ), or adjusted to the highest $n$-alkane peak to illustrate the abundance of the key compound, (20R)-5 $\alpha, 14 \alpha, 17 \alpha(\mathrm{H})$-cholestane, relative to other pyrolysis products (Extended Data Fig. 4a). This molecule was identified by comparison against, and co-injection of, a commercially available standard (Chiron Laboratories AS). Identification of the $20 \mathrm{~S}$ isomer was based on its retention time and mass spectral characteristics; minor co-elution with other isomers may have occurred. The gas chromatograph was equipped with a Phenomenex Zebron ZB-5 capillary column ( $30 \mathrm{~m}, 0.1 \mu \mathrm{m}$ film thickness, inner diameter $0.25 \mathrm{~mm}$ ), and used helium $(1.7 \mathrm{ml} / \mathrm{min})$ as the carrier gas. Pyrolysis products were flushed onto the GC column at an injector temperature of $300^{\circ} \mathrm{C}$, and a split rate of 20 . The GC oven temperature was ramped from $40(3 \mathrm{~min})$ to $310^{\circ} \mathrm{C}$ at $10^{\circ} \mathrm{C} \mathrm{min}{ }^{-1}$, and was held for $15 \mathrm{~min}$. Electron-ionization mass spectra were recorded at $70 \mathrm{eV}$ in full-scan mode (mass range $50-450$, scan time $0.35 \mathrm{~s}$ ).

Alkaline hydrogen peroxide oxidation. Untreated fossil and sediment samples were mechanically ground into a powder. Approximately $2-6 \mathrm{mg}$ of each sample was heated with $500 \mu \mathrm{l} 6 \mathrm{M} \mathrm{HCl}$ at $110^{\circ} \mathrm{C}$ for $16 \mathrm{~h}$ in a 10 -ml test tube. Following addition of $1 \mathrm{ml}$ water, the tube was centrifuged at $14,000 \mathrm{~g}$ for $10 \mathrm{~min}$, and the residue then washed with $1 \mathrm{ml}$ water and subjected to alkaline hydrogen peroxide oxi- dation ${ }^{36}$. One hundred microlitres of water, $375 \mu \mathrm{l} 1 \mathrm{M} \mathrm{K}_{2} \mathrm{CO}_{3}$ and $25 \mu \mathrm{l} 30 \% \mathrm{H}_{2} \mathrm{O}_{2}$ were added to each tube. Following vigorous mixing at $25^{\circ} \mathrm{C}$ for $20 \mathrm{~h}$, the residual $\mathrm{H}_{2} \mathrm{O}_{2}$ was decomposed by adding $50 \mu \mathrm{l} 10 \% \mathrm{Na}_{2} \mathrm{SO}_{3}$, and the resulting mixture acidified with $140 \mu \mathrm{l} 6 \mathrm{M} \mathrm{HCl}$. The oxidation mixture was centrifuged at $10,000 \mathrm{~g}$ for $1 \mathrm{~min}$, and an aliquot $(80 \mu \mathrm{l})$ of the supernatant was injected directly into a high-performance liquid chromatography (HPLC) system. The setup included a JASCO 880-PU liquid chromatograph (JASCO), a Shiseido C18 column (Capcell Pak, Type MG; $4.6 \times 250 \mathrm{~mm}$; 5- $\mu \mathrm{m}$ particle size; Shiseido), and a JASCO UV detector, which was monitored at $269 \mathrm{~nm}$. The mobile phases comprised $0.1 \mathrm{M}$ potassium phosphate buffer ( $\mathrm{pH}$ 2.1): methanol, $99: 1$, at $45^{\circ} \mathrm{C}$ for PTCA and PDCA and $0.4 \mathrm{M} \mathrm{HCOOH}$ : methanol, $85: 15$, at $35^{\circ} \mathrm{C}$ for PTeCA.

Amino acid analysis. Powdered samples $(\sim 6-10 \mathrm{mg})$ were placed in vacuum hydrolysis test tubes (Kontes Glass, \#896860-8910), and $1 \mathrm{ml} 6 \mathrm{M} \mathrm{HCl}$ containing $1 \%$ phenol was added to each tube. The tubes were then evacuated, sealed and placed in an oil bath at $110^{\circ} \mathrm{C}$ for $24 \mathrm{~h}$. The hydrolysates were extracted twice with $2 \mathrm{ml}$ ether, and evaporated to dryness under vacuum. The residues were then dissolved in 200-400 $\mathrm{ll} 0.1 \mathrm{M} \mathrm{HCl}$, and centrifuged at 10,000g. Aliquots (4-5 $\mu \mathrm{l}$ ) were applied to LC/MS for quantitative amino acid analysis. Two solvent systems (condition I and II) were used because of variable amino acid sensitivity: condition I for alanine, glutamic acid, glycine and serine; and condition II for all other amino acids. Standard amino acid solutions of 10 and $50 \mu \mathrm{M}$ in $0.1 \mathrm{M} \mathrm{HCl}$ were used as references. Liquid chromatographic conditions included an Agilent 1200 HPLC system (Hewlett Packard) with an Intrada Amino Acid $(2 \times 75-\mathrm{mm})$ (Imtakt) column, and a sequence of solvents: condition I, A = MeCN:THF:25 $\mathrm{mM} \mathrm{HCOONH}_{4}: \mathrm{HCOOH}$ (9:75:16:0.3), B $=\mathrm{MeCN} 100 \mathrm{mM} \mathrm{HCOONH}_{4}$ (20:80), 0\% B (0-7 min), 0-17\% B (7-21 min), 100\% B (21-35 min); condition II, $\mathrm{A}=\mathrm{MeCN}: \mathrm{HCOOH}(100: 0.1), \mathrm{B}=100 \mathrm{mM} \mathrm{HCOONH}_{4}, 15 \% \mathrm{~B}$ (0-3 min), $15-100 \% \mathrm{~B}(3-20 \mathrm{~min}), 100 \% \mathrm{~B}(20-24 \mathrm{~min})$. The flow rate was set at $0.2 \mathrm{ml} / \mathrm{min}$. Mass spectrometry conditions incorporated a HCTplus (Bruker Daltonics) with an ESI positive source, an ionization nebulizer at $30 \mathrm{psi}$, dry gas at $7.01 / \mathrm{min}$, dry temperature at $320^{\circ} \mathrm{C}$ and an ion-trap analyser.

Statistics and reproducibility. Forty-one samples were collected from MH 432 and its associated matrix (Fig. 1b); 18 of these were demineralized. All samples were photographically documented (Figs. 2a, e-i, 3a-c, 5a and Extended Data Fig. 2a), together with comparative tissues from extant vertebrates (Fig. $2 q-s$ and Extended Data Fig. 9e). The following experiments were repeated independently with similar results. Light microscopy (histological sections): MH 432 (Figs. 2l, 4c, 5b, i and Extended Data Figs. 8b, 10d) nine samples; Dermochelys (Figs. 2t, 31-n and Extended Data Fig. 9a-d) nine samples; and Phocoena (Extended Data Fig. 9g, i, j) six samples. FEG-SEM: MH 432 (Figs. 2j, k, m, p, 3e-g, 5c and Extended Data Figs. 3b, c, 8c, d) eight samples. EDX: MH 432 (Fig. 5d and Extended Data Figs. 2f, g, 3d) eight samples. TEM: MH 432 (Figs. 2n, o, 3h-j, 5e, f and Extended Data Figs. $2 \mathrm{~b}-\mathrm{e}, 8 \mathrm{i}, \mathrm{j}, 10 \mathrm{e}-\mathrm{h}, \mathrm{j}$ ) nine samples; Dermochelys (Fig. 3o-q, ) nine samples; and Phocoena (Extended Data Fig. 9k-m) six samples. Immunohistochemistry in Fig. 4e-n: for MH 432 sample 13, tropomyosin four times, ostrich haemoglobin four times and alligator haemoglobin three times; for MH 432 sample 8, $\alpha$-keratin four times; and for MH 432 sample 12, immunogold $\alpha$-keratin three times. Immunohistochemistry in Fig. 5g, h: MH 432 sample 13a, $\alpha$-keratin two times. Immunohistochemistry in Extended Data Fig. 7: MH 432 samples 8 and 12a, elastin two times, actin three times, collagen two times, and $\beta$-keratin two times; Dermochelys, tropomyosin two times, collagen two times, alligator haemoglobin two times, ostrich haemoglobin two times, $\alpha$-keratin four times and immunogold $\alpha$-keratin three times. Immunohistochemistry in Extended Data Fig. 8e-h: MH 432 sample 7, ostrich haemoglobin four times and alligator haemoglobin three times. SRXTM in Fig. 3d and Extended Data Fig. 3a, five times. Infrared microspectroscopy: the intensity map (Fig. 5j) was generated from 128 individual scans; each spectrum in Fig. $5 \mathrm{k}$ represents an average of three spots; and the melanophore spectrum (Extended Data Fig. 3g) is an average of 32 individual scans (repeated twice). NanoSIMS: melanophore (Fig. 3k and Extended Data Fig. 3e) six times; light microscopy section (Fig. $4 \mathrm{~d}$ and Extended Data Fig. $2 \mathrm{~h}$ ) four times. ToF-SIMS: eumelanin identification (Fig. 3s) four times; hydrocarbon and peptide/ protein identification (Fig. 4a and Extended Data Fig. 5a, b) nine times; blubber (Fig. 5l-n and Extended Data Fig. 5c) four (positive ions) and six (negative ions) times; and liver (Extended Data Fig. 8k) six times. Py-GC/MS: three (integument, liver and sediment) and four (remote sediment) times (Fig. 4b and Extended Data Fig. 4). Alkaline hydrogen peroxide oxidation: two (liver, belly skin and sediment) and three (flank skin) times (Fig. 3r and Extended Data Fig. 3f; data in Fig. 3r are centre values with standard error of mean). Amino acid analysis: two times (Extended Data Fig. 6 and Supplementary Table 2). The other experimentsincluding the SRS-XRF mapping (Fig. 1c and Extended Data Fig. 1n, o), ultraviolet imaging (Extended Data Fig. 1d-m), maturation experiments (Extended Data Fig. 9b, f-q) and TEM of bacteria (Extended Data Fig. 10i) - were not repeated. Reporting summary. Further information on research design is available in the Nature Research Reporting Summary linked to this paper. 


\section{RESEARCH ARTICLE}

\section{Data availability}

The Stenopterygius specimen examined in this study (MH 432) is permanently accessioned in the collections of Urweltmuseum Hauff, Holzmaden, Germany. The data supporting our findings are available from the corresponding author upon reasonable request.
35. Thiel, V. \& Sjövall, P. in Principles and Practice of Analytical Techniques in Geosciences (ed. Grice, K.) 122-170 (Royal Society of Chemistry, Cambridge, 2015).

36. Ito, S. et al. Acid hydrolysis reveals a low but constant level of pheomelanin in human black to brown hair. Pigment Cell Melanoma Res. 31, 393-403 (2018). 

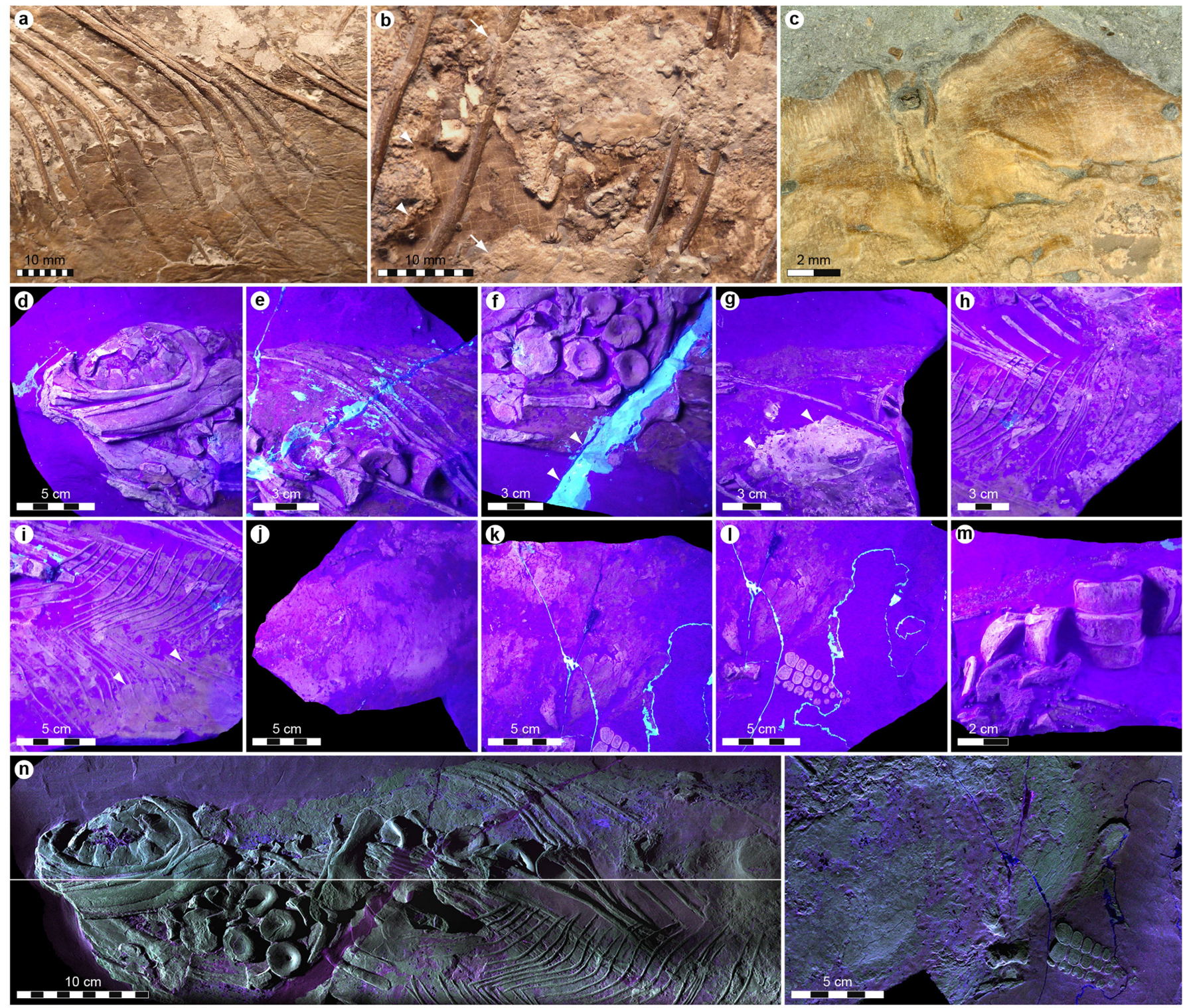

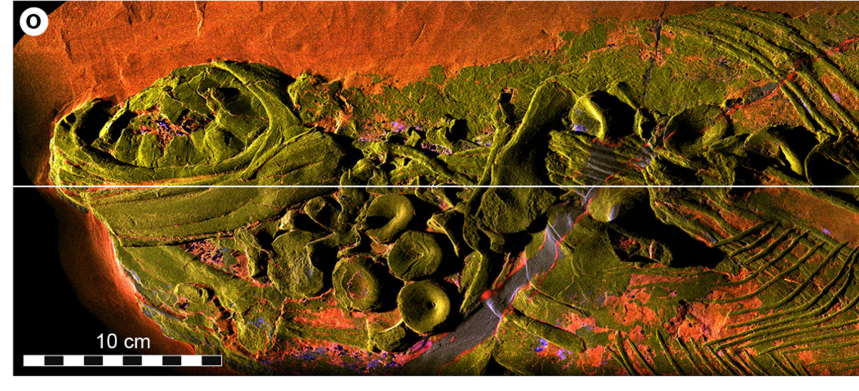

Extended Data Fig. 1 | Regular, ultraviolet light and SRS-XRF images of MH 432. a, Skin compressed onto the diagenetically flattened gastralia basket. b, Amorphous adipocere (arrows) external to the gastralia and liver residue (arrowheads) within the abdominal cavity. c, Fibrous muscle or connective tissue on the left side of the trunk. $\mathbf{d}-\mathbf{m}$, Some of the anatomical features, and the stone putty used to reassemble the individual blocks, are enhanced under ultraviolet light. Note the differences in

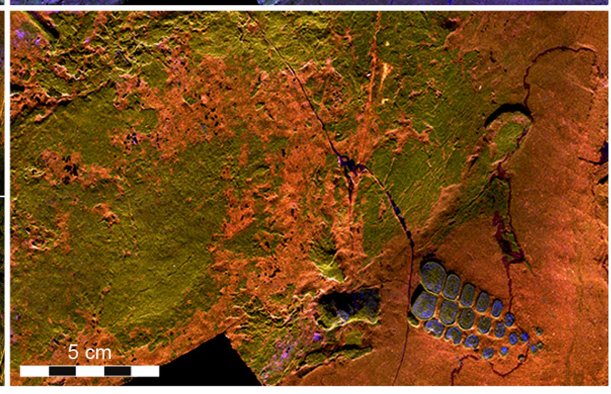

fluorescence between the putty (arrowheads in f), internal structures (arrowheads in $\mathbf{g}$ ) and integument (arrowheads in i). n, SRS-XRF falsecolour images showing the spatial distribution of silicon (magenta), phosphorous (green) and copper (blue). o, SRS-XRF false-colour images showing the spatial distribution of iron (red), sulfur (yellow) and zinc (blue). The lack of co-localization between copper, zinc and the preserved soft tissues might result from calcium phosphate overprinting. 

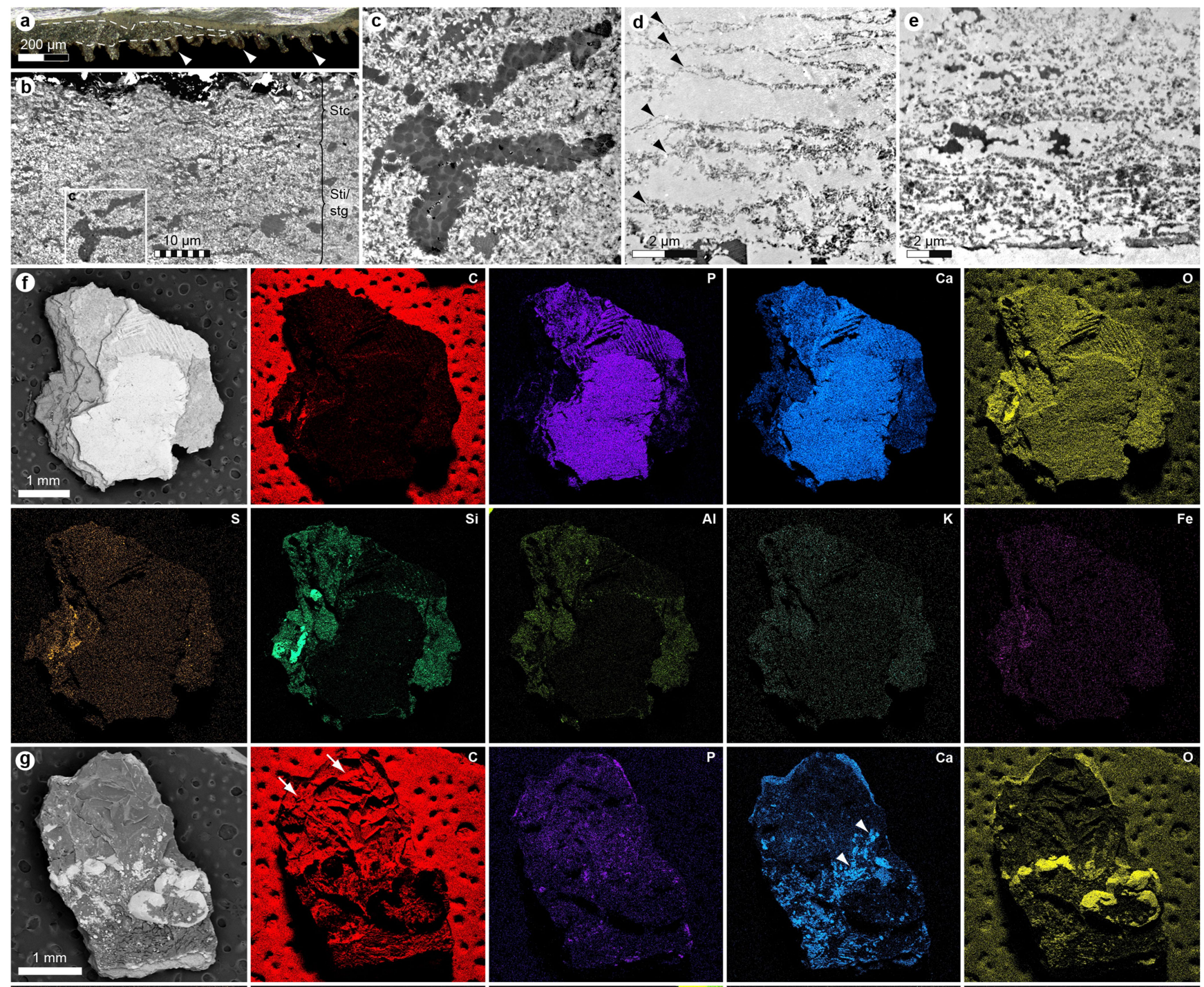

\section{$\mathrm{Fe}$}

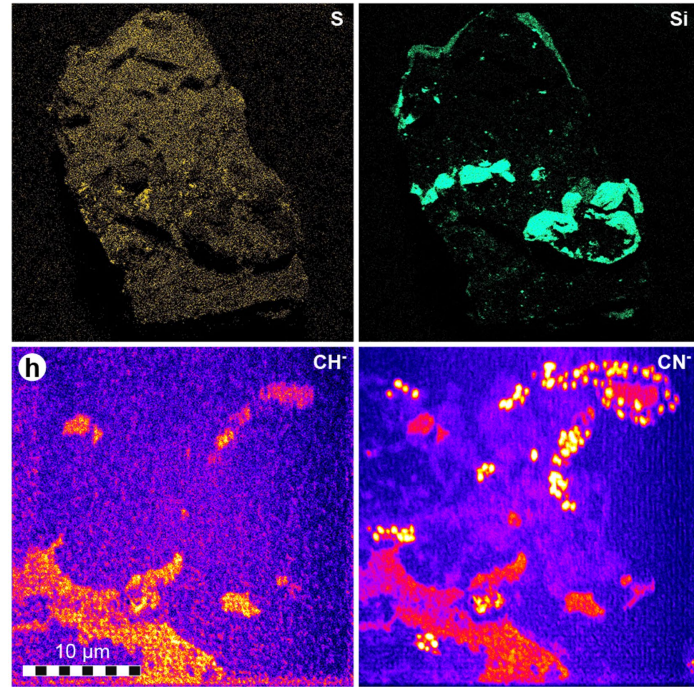

ii
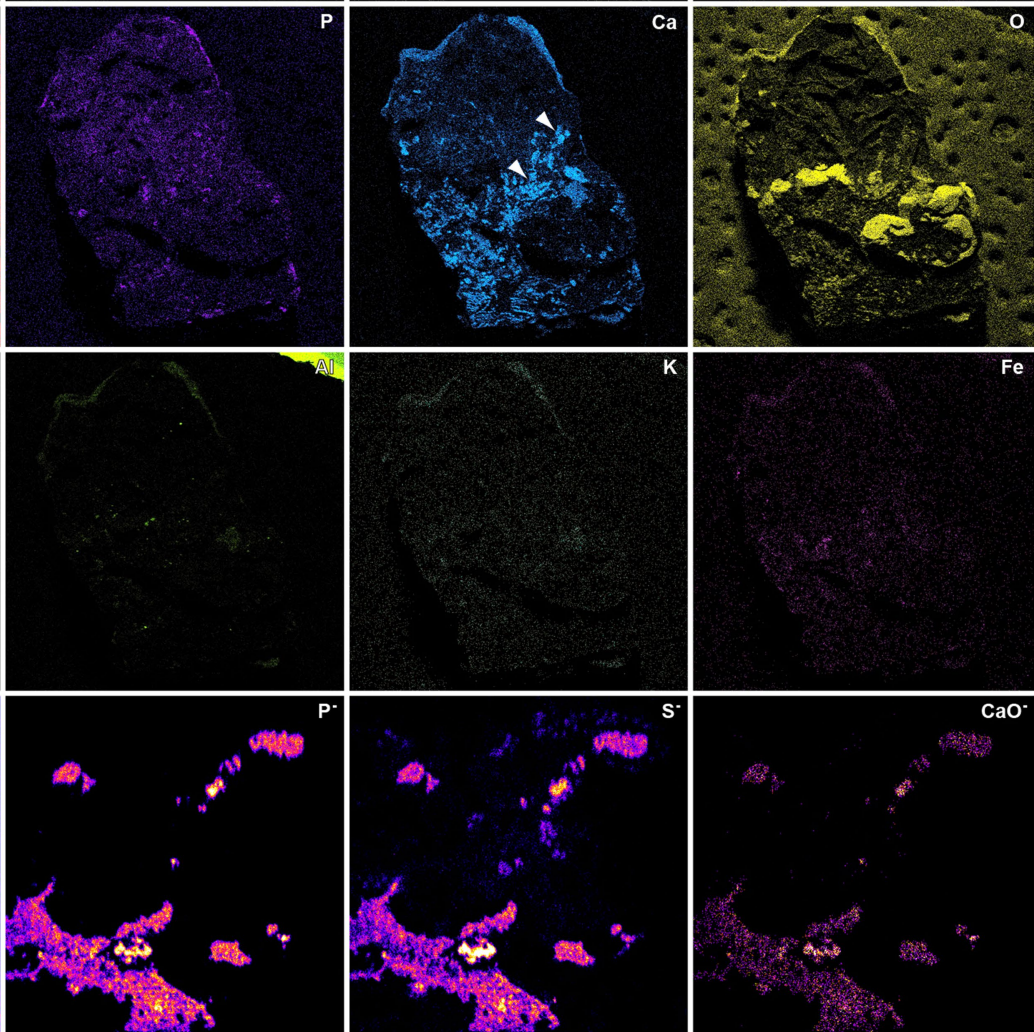

Extended Data Fig. 2 | See next page for caption. 
Extended Data Fig. 2 Light microscopy, TEM, EDX and NanoSIMS data from MH 432 integument. a, Transverse section through demineralized epidermis (sample 13a) showing epidermal ridges (arrowheads) and invasive sediments (dashed line). b, TEM micrograph through the stratified epidermis (sample 13). Stc, stratum corneum; sti/ stg, stratum intermedium and/or stratum germinativum. c, Enlargement of a branched epidermal melanophore. d, Squamous keratinocytes from between the stratum intermedium and stratum corneum (sample 10); these become progressively flattened towards the exterior surface (top). Arrowheads, cellular envelopes. e, TEM section through the fibrous superficial dermis (sample 12a). f, Back-scattered electron micrograph and single-element EDX maps of untreated integument in external view. Coloured images illustrate the relative abundance of each element, with higher intensities indicating greater abundance. Note the enrichment of calcium and phosphorous in the fossilized epidermis and dermis. Intensities from carbon derive primarily from the underlying conductive tape. Al, aluminium (lime); C, carbon (red); Ca, calcium (blue); Fe, iron (violet); $\mathrm{K}$, potassium (turquoise blue); O, oxygen (yellow); $\mathrm{P}$, phosphorous (purple); S, sulfur (orange); $\mathrm{Si}$, silicon (turquoise). g, Backscattered electron micrograph and single-element EDX maps of untreated integument in internal view (colours as in $\mathbf{f}$ ). Note high levels of carbon (arrows) and localized enrichment of calcium (arrowheads) in the blubber and subjacent fibrous tissue. Intensities from silicon and oxygen derive primarily from authigenic silica minerals. h, High-resolution NanoSIMS images acquired from demineralized skin showing the distribution of $\mathrm{CH}^{-}, \mathrm{CN}^{-}, \mathrm{P}^{-}, \mathrm{S}^{-}$and $\mathrm{CaO}^{-}$(sample 13a). $\mathrm{CN}^{-}$-rich microbodies are melanosomes (see Extended Data Fig. 3e). 

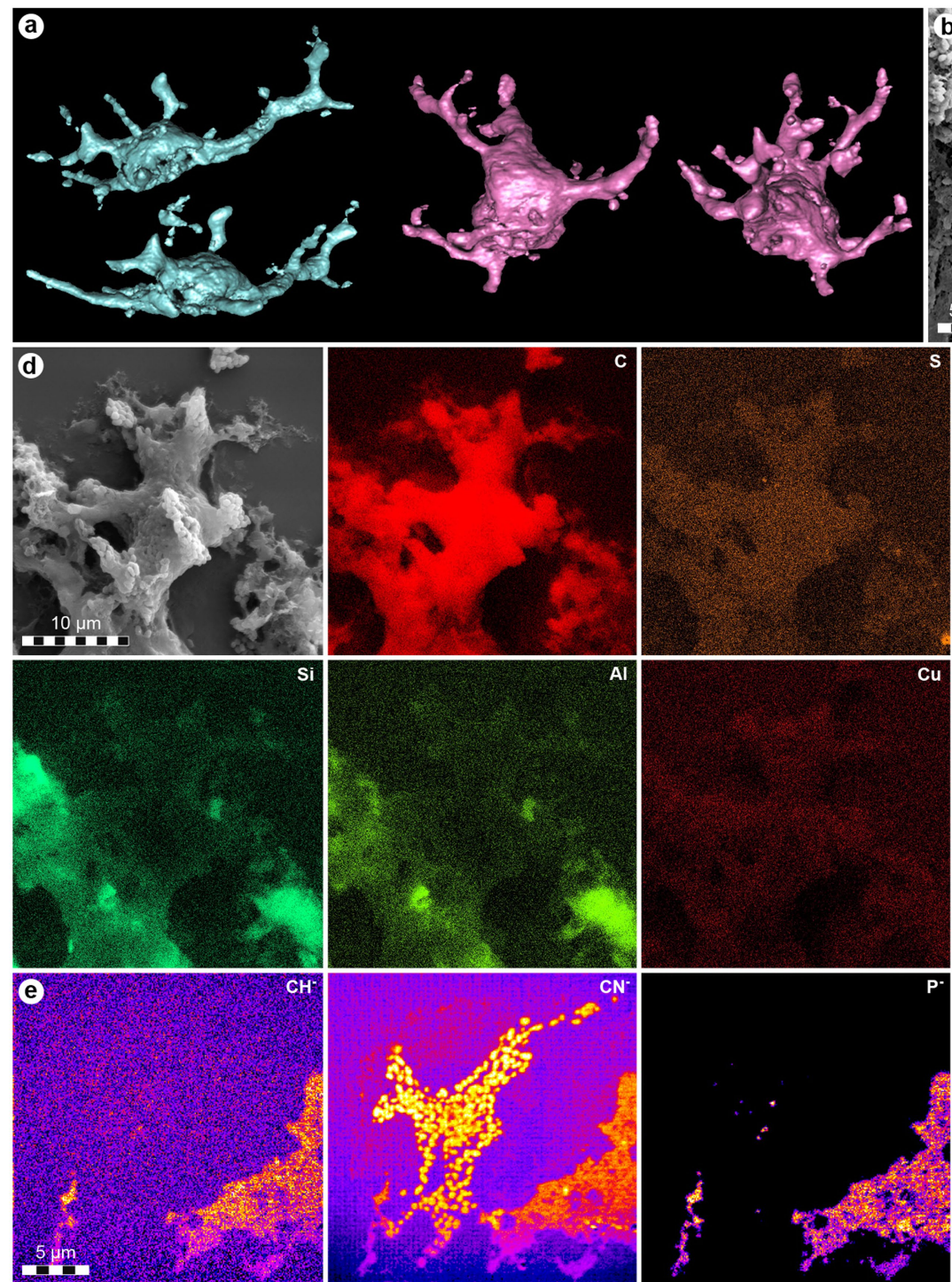

g

$\mathbf{f}$

\begin{tabular}{cccc}
\hline \multicolumn{4}{c}{ Eumelanin markers (ng/mg) } \\
Sample & PTCA & PDCA & PTeCA \\
\hline $7 \mathrm{a}$ & 1.98 & 1.52 & 5.03 \\
$7 \mathrm{a}$ & 1.99 & 1.80 & 8.01 \\
$10 \mathrm{a}$ & 0.52 & 0.50 & 1.20 \\
$10 \mathrm{a}$ & 1.11 & 0.97 & 3.09 \\
$10 \mathrm{~b}$ & 0.72 & 0.65 & 3.51 \\
$13 \mathrm{a}$ & 0.80 & 0.30 & 2.39 \\
$13 \mathrm{~d}$ & 1.26 & 0.47 & 3.35 \\
$14 \mathrm{a}$ & 0.50 & 0.45 & 0.82 \\
$14 \mathrm{a}$ & 0.51 & 0.21 & 1.44 \\
\hline
\end{tabular}
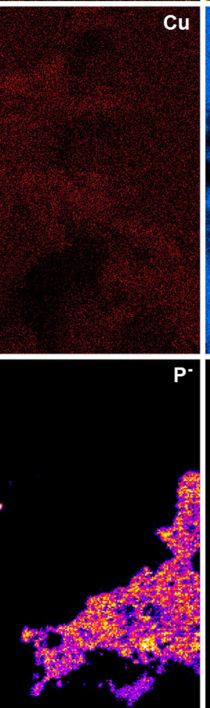
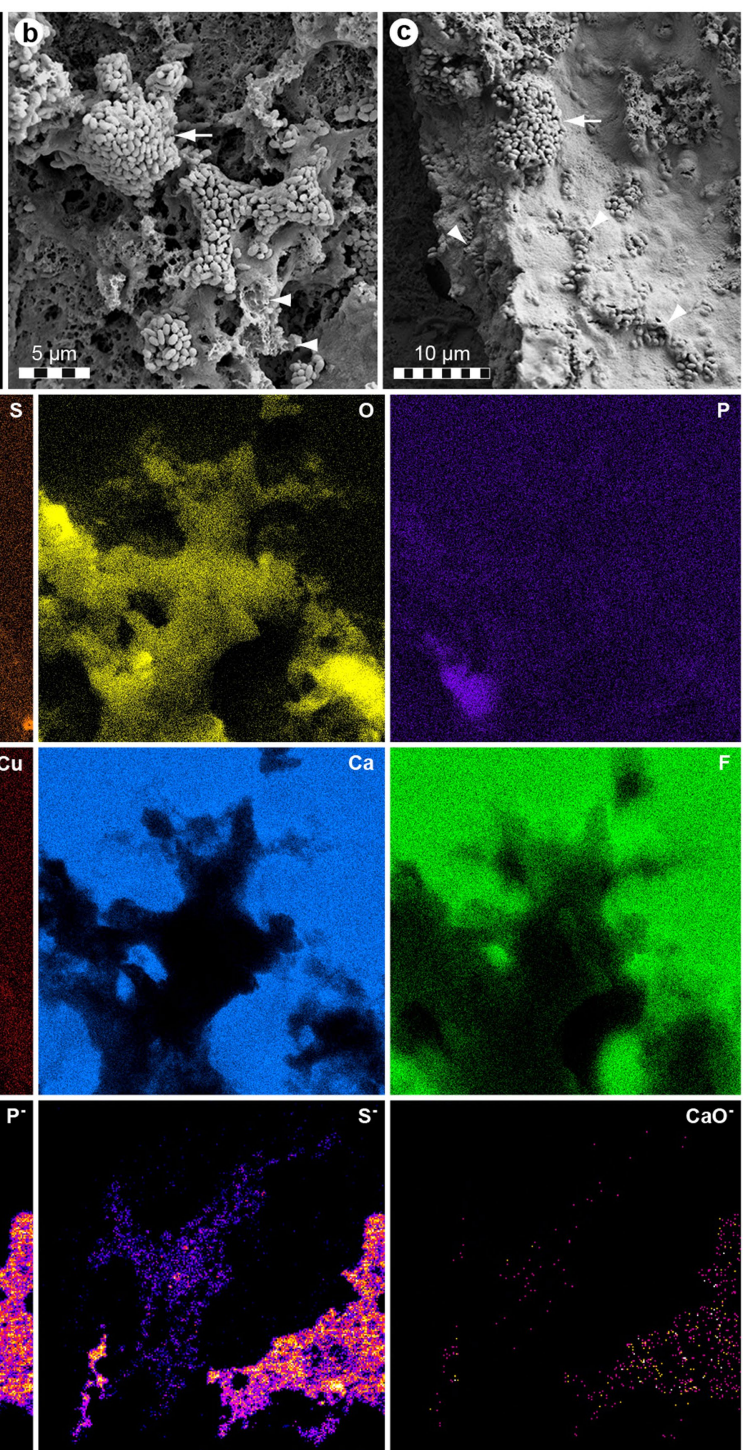

$\mathrm{CaO}^{-}$
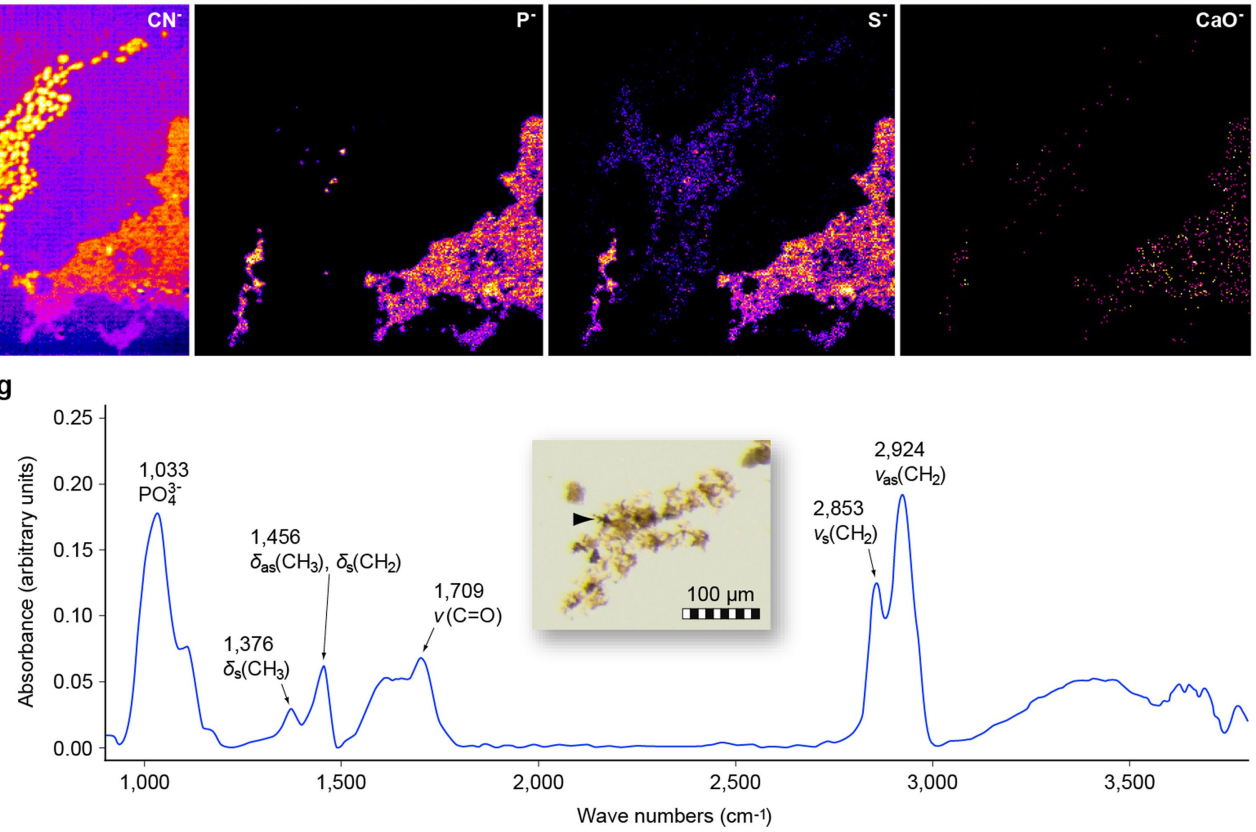

Extended Data Fig. 3 | Three-dimensional visualization and chemistry of MH 432 melanophores. a, SRXTM renderings of branched melanophores (sample 18). b, FEG-SEM micrograph of a dermal melanophore and adjacent organic matter recovered from demineralized integument (sample 13a). Note the remnant cell body (arrow) and external moulds of disrupted pigment organelles in the polymerized matrix of one dendrite (arrowheads). c, FEG-SEM micrograph of a dermal melanophore and adjacent organic matter from demineralized integument (sample 13). Note the clustered melanosomes that represent the cell body (arrow), and dendritic extensions packed with pigment organelles (arrowheads). d, Back-scattered electron micrograph and single-element EDX maps of the melanophore in Fig. 3e-g. Coloured images illustrate the relative abundance of each element, with higher intensities indicating greater abundance. Note the enrichment of carbon and, to a lesser extent, sulfur and oxygen in the fossil pigment cell. Intensities from calcium and fluoride derive from the underlying spectrophotometric window (see $\mathbf{g}$ ). Al, aluminium (lime); C, carbon (red); Ca, calcium (blue); $\mathrm{Cu}$, copper (dark red); F, fluoride (green); O, oxygen (yellow); P, phosphorous (purple); $\mathrm{S}$, sulfur (orange); Si, silicon (turquoise). e, High-resolution NanoSIMS images of the melanophore in Fig. 3h-k showing the distribution of $\mathrm{CH}^{-}, \mathrm{CN}^{-}, \mathrm{P}^{-}, \mathrm{S}^{-}$and $\mathrm{CaO}^{-}$. Note the relatively high levels of $\mathrm{CN}^{-}$and $\mathrm{S}^{-}$in the melanosomes, whereas the surrounding matrix also contains measurable amounts of $\mathrm{CH}^{-}$and $\mathrm{P}^{-}$. f, The alkaline hydrogen peroxide oxidation products PTCA, PDCA and PTeCA (Fig. 3r) from samples 7a (two batches), 10a (two batches), 10b, 13a, 13d and 14a (two batches). g, Infrared spectrum from the melanophore in Fig. $3 \mathrm{e}-\mathrm{g}$ (arrowhead in the inset light microscopy image) showing peaks attributed to hydrocarbons and phosphate. 
a

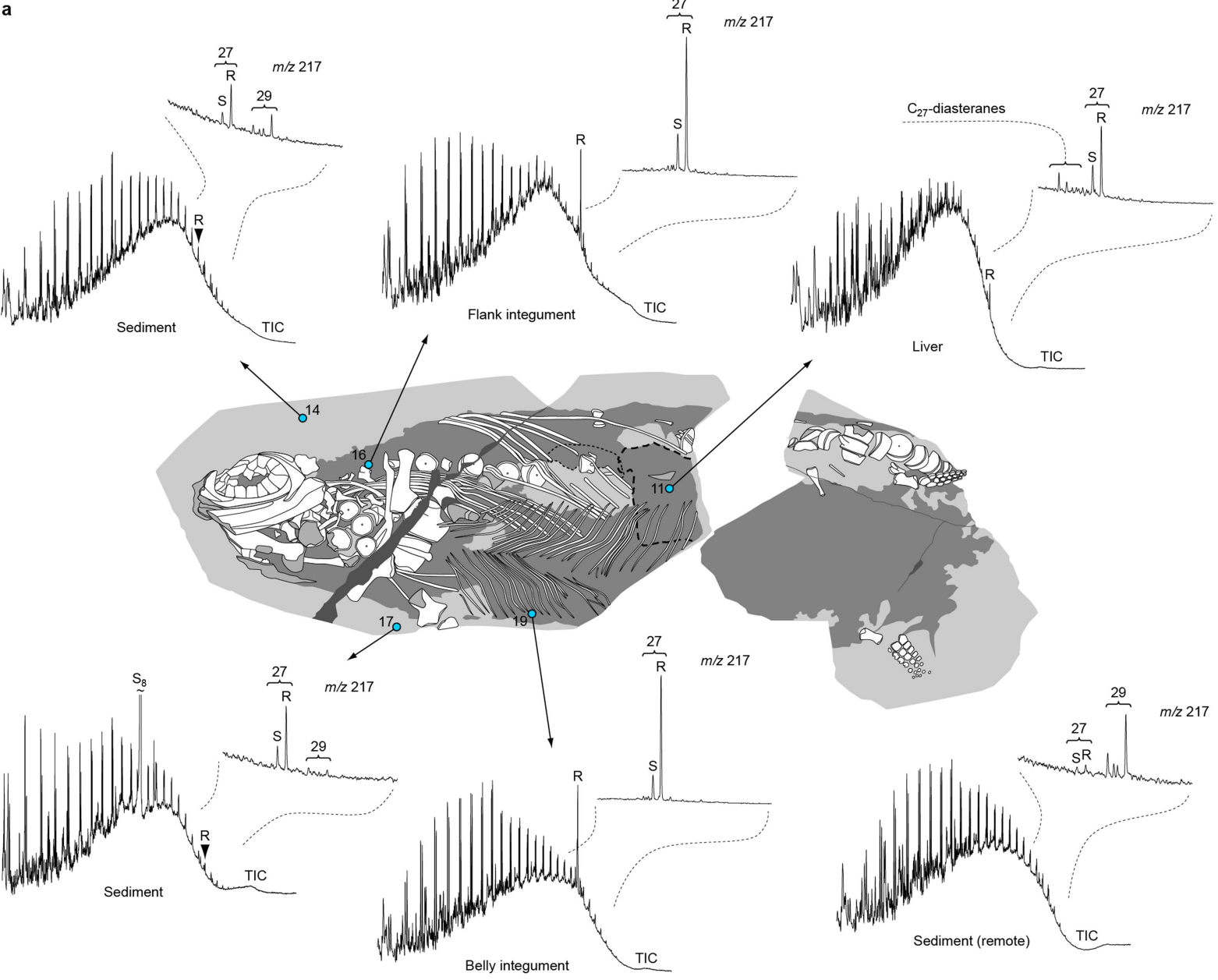

b

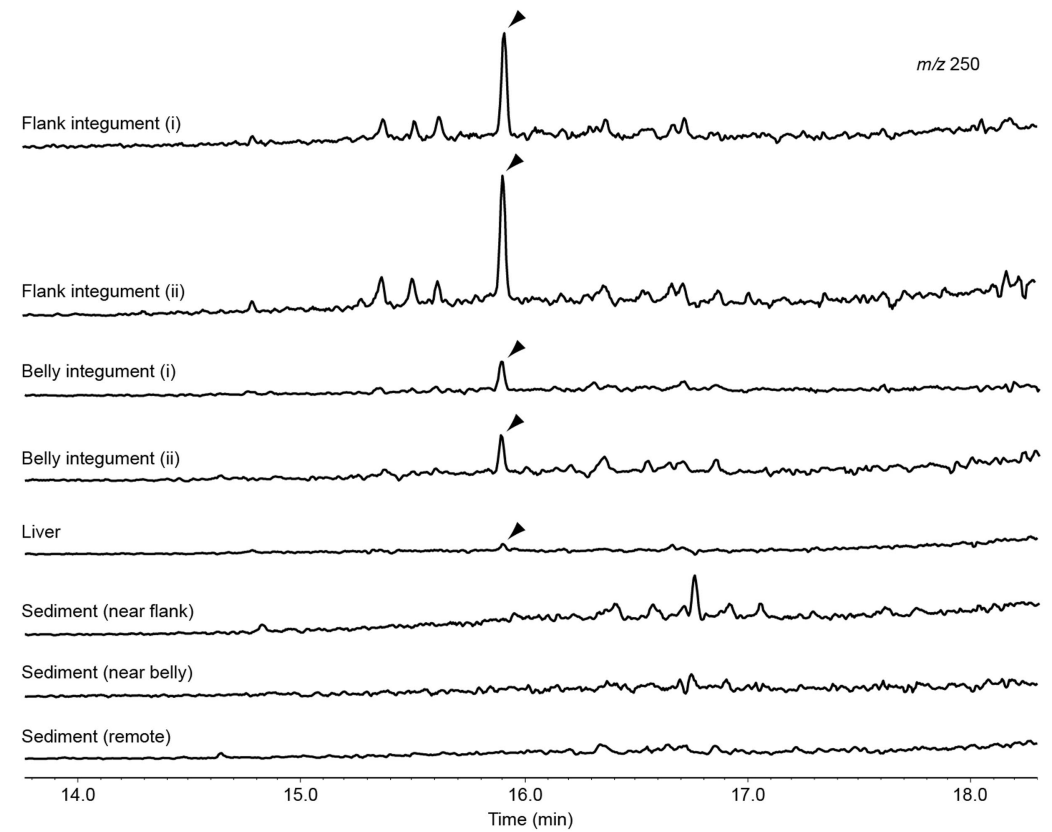

Extended Data Fig. 4 | See next page for caption. 


\section{RESEARCH ARTICLE}

Extended Data Fig. 4 | Pyrolysis data collected at $560^{\circ} \mathrm{C}$ for $10 \mathrm{~s}$, from the soft tissues of MH 432. a, Py-GC/MS chromatograms obtained from MH 432 (TIC, total ion currents). The prominent peak series in each sample represents homologous $n$-alkenes and $n$-alkanes; chromatograms are normalized to the highest of these peaks. Inset ion chromatograms $(\mathrm{m} / z 217)$ illustrate the distribution of eukaryote-derived steranes, with 27 and 29 denoting carbon numbers. S and R denote (20S) $-5 \alpha, 14 \alpha, 17 \alpha(\mathrm{H})$ and (20R) $-5 \alpha, 14 \alpha, 17 \alpha(\mathrm{H})$ isomers, respectively. Abundant $\mathrm{C}_{27}$-steranes (cholestanes) in the integument constitute diagenetic products of ichthyosaur cholesterol. The predominant $20 \mathrm{R}$ isomer is also indicated in the TICs to illustrate its abundance among the total pyrolysates. $\mathrm{C}_{29^{-}}$ steranes (stigmastanes) reflect background sedimentation from algae and/or terrestrial plants. Note the high amount of cholestanes in the integument and greater abundance of stigmastanes in the host rock. Also note the higher intensities of aromatics (relative to aliphatics), diasteranes (relative to regular steranes) and a stronger unresolved complex mixture in the liver, reflecting original compositional differences and/or enhanced biodegradation. b, Py-GC/MS ion chromatograms $(\mathrm{m} / z 250$, normalized to sample weight) showing a compound tentatively identified as $n$-octadecadiene (arrowheads, $n$ - $\mathrm{C}_{18: 2}$ ). This molecule is interpreted as a pyrolysis product of kerogen-bound $n$-octadecenyl $\left(n-\mathrm{C}_{18: 1}\right)$ moieties potentially originating from oleic acid $\left(\mathrm{C}_{18: 1} \omega 9 c\right)$, the most abundant monoenoic fatty acid in extant vertebrates. Note the localized occurrence within the flank integument (where the blubber is best preserved). Replicate sample measurements (denoted by $\mathrm{i}$ and ii) are provided to demonstrate reproducibility. 

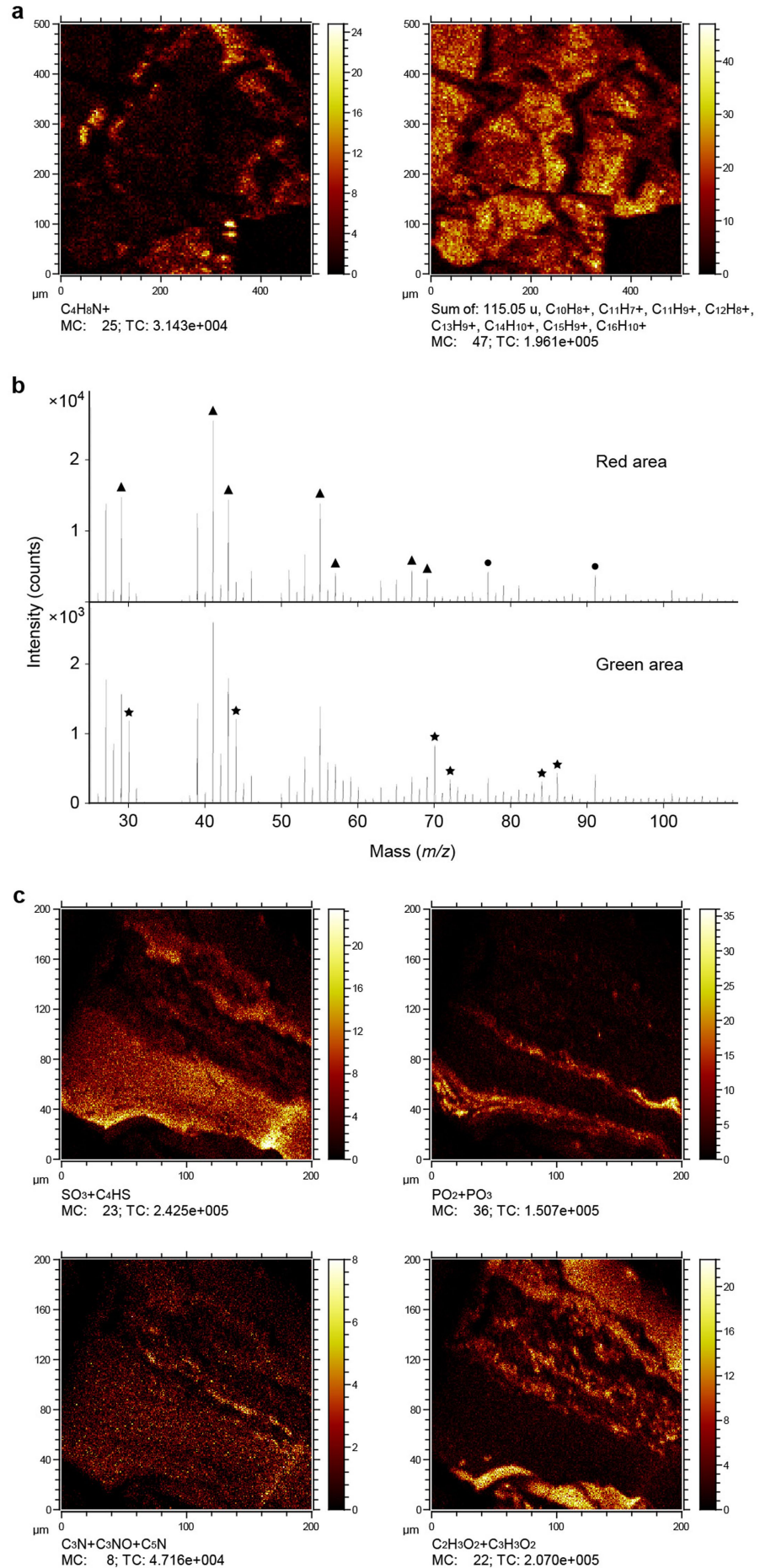

Extended Data Fig. 5 | ToF-SIMS images and spectra from MH 432 integument. a, Images of positive ions (sample 2) that are characteristic of (from left to right) peptides/proteins $\left(\mathrm{C}_{4} \mathrm{H}_{8} \mathrm{~N}^{+}, \mathrm{m} / z 70\right)$, polyaromatic hydrocarbons $\left(\mathrm{C}_{9} \mathrm{H}_{7}{ }^{+}, m / z 115 ; \mathrm{C}_{10} \mathrm{H}_{8}{ }^{+}, m / z 128 ; \mathrm{C}_{11} \mathrm{H}_{7}{ }^{+}, m / z 139\right.$; $\mathrm{C}_{11} \mathrm{H}_{9}{ }^{+}, m / z 141 ; \mathrm{C}_{12} \mathrm{H}_{8}{ }^{+}, m / z 152 ; \mathrm{C}_{13} \mathrm{H}_{9}{ }^{+}, m / z 165 ; \mathrm{C}_{14} \mathrm{H}_{10}{ }^{+}, m / z 178$; $\mathrm{C}_{15} \mathrm{H}_{9}{ }^{+}, m / z 189$; and $\mathrm{C}_{16} \mathrm{H}_{10}{ }^{+}, m / z$ 202) and the sedimentary matrix $\left(\mathrm{Al}^{+}\right.$, $m / z 27 ; \mathrm{Si}^{+}, m / z 28$; and $\mathrm{K}^{+}, m / z 39$ ), along with a three-colour overlay image of these ions in which green represents proteinaceous matter, red represents polyaromatic hydrocarbons and blue represents sediment. b, Positive ion spectra from selected regions of interest indicated in the three-colour overlay image in a (green demarcations highlight areas dominated by proteinaceous matter; red lines frame regions rich in polyaromatic hydrocarbons). Characteristic aliphatic and polyaromatic hydrocarbon peaks are indicated by triangles and circles, respectively,
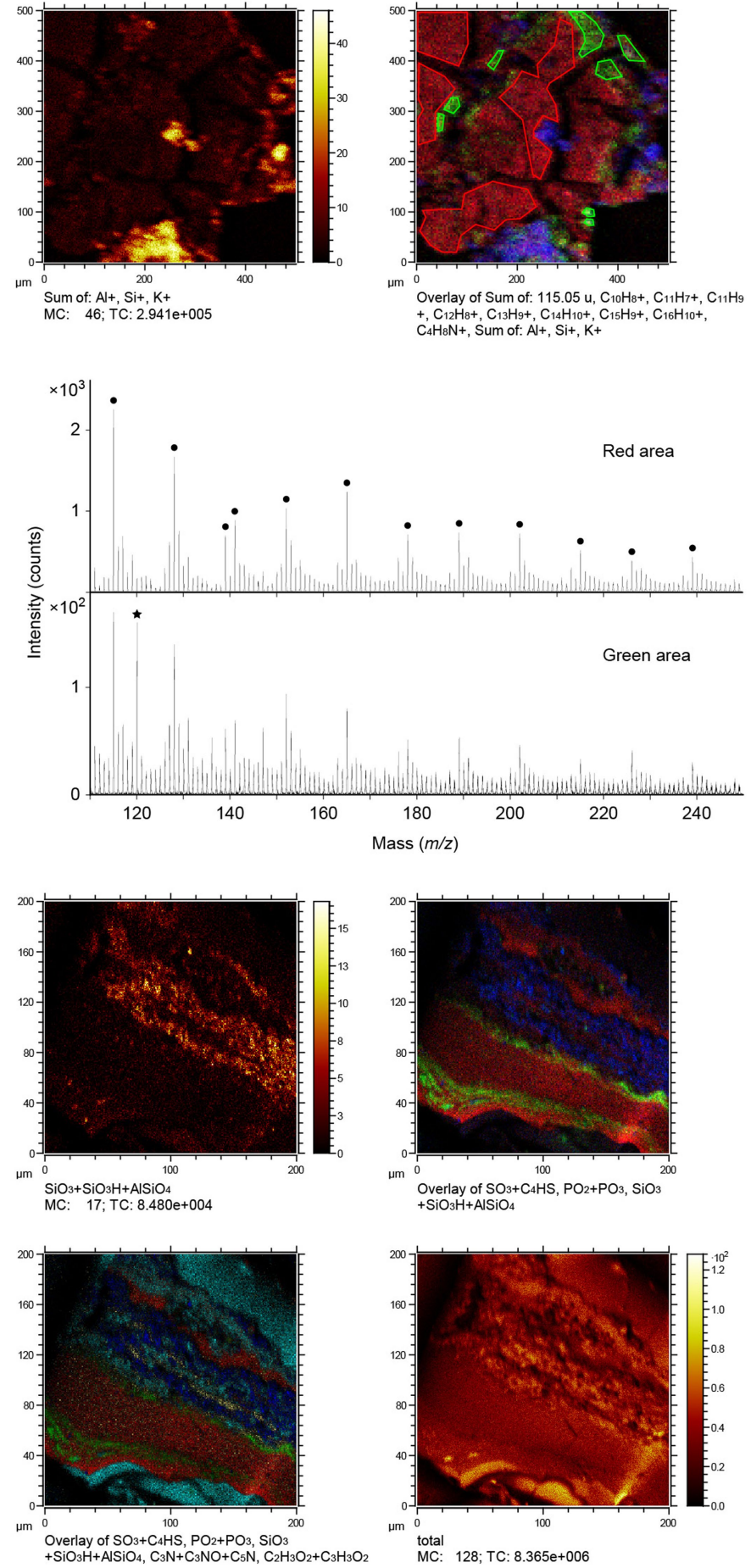

in the top spectrum (red regions of interest), whereas typical protein fragment ions are denoted by stars in the bottom spectrum (green regions of interest; see Supplementary Information). c, Negative ion images of sample 13a (see Fig. $5 \mathrm{~m}$ ) representing (top row, from left to right) sulfurcontaining materials $\left(\mathrm{SO}_{3}{ }^{-}, \mathrm{m} / z 80\right.$ and $\mathrm{C}_{4} \mathrm{HS}^{-}, \mathrm{m} / z$ 81), phosphate $\left(\mathrm{PO}_{2}{ }^{-}\right.$, $\mathrm{m} / z 63$ and $\mathrm{PO}_{3}{ }^{-}, \mathrm{m} / z$ 79) and the sedimentary matrix $\left(\mathrm{SiO}_{3}{ }^{-}, \mathrm{m} / z\right.$ 76; $\mathrm{SiHO}_{3}{ }^{-}, m / z$ 77; and $\mathrm{AlSiO}_{4}{ }^{-}, m / z$ 119), together with a three-colour overlay image of these ions in red, green and blue, respectively. The bottom row shows the spatial distribution of ions representing eumelanin $\left(\mathrm{C}_{3} \mathrm{~N}^{-}\right.$, $m / z 50 ; \mathrm{C}_{3} \mathrm{NO}^{-}, m / z 66$; and $\left.\mathrm{C}_{5} \mathrm{~N}^{-}, m / z 74\right)$ and epoxy $\left(\mathrm{C}_{2} \mathrm{H}_{3} \mathrm{O}_{2}{ }^{-}, m / z 59\right.$ and $\mathrm{C}_{3} \mathrm{H}_{3} \mathrm{O}_{2}{ }^{-}, m / z 71$ ), along with a five-colour overlay image featuring sulfur-containing ions (red), phosphate (green), eumelanin (yellow), epoxy (cyan) and sediment (blue); the total ion image is shown on the far right. 

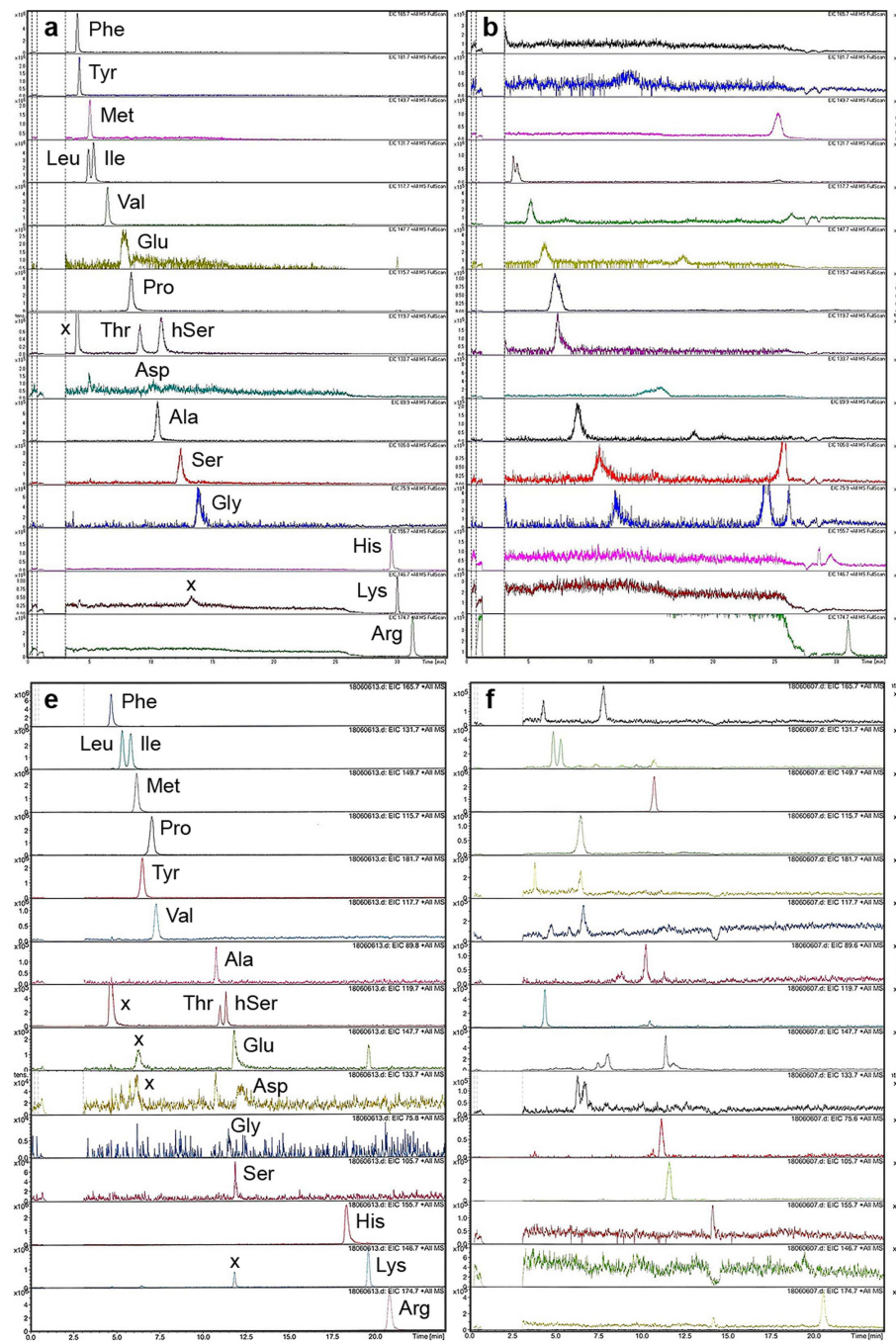

Extended Data Fig. 6 | Amino acid analysis data from MH 432.

a-d, Liquid chromatography condition I. a, Standard amino acids (200 pmol per $4 \mu \mathrm{l})$. b, Sample 7a, liver (a $4-\mu \mathrm{l}$ portion of $8.51 \mathrm{mg}$ per

$170 \mu \mathrm{l}$ ). c, Sample 13d, integument (a $4-\mu \mathrm{l}$ portion of $10.27 \mathrm{mg}$ per $206 \mu \mathrm{l}$ ).

d, Sample 14a, sediment (a $4-\mu \mathrm{l}$ portion of $10.05 \mathrm{mg}$ per $201 \mu \mathrm{l}$ ).

e-h, Liquid chromatography condition II. e, Standard amino acids (200 pmol per $4 \mu \mathrm{l}$ ). f, Sample 7 a, liver (a $5-\mu \mathrm{l}$ portion of $8.51 \mathrm{mg}$ per $340 \mu \mathrm{l}$ ). g, Sample 13d, integument (a $5-\mu \mathrm{l}$ portion of $10.27 \mathrm{mg}$ per $411 \mu \mathrm{l}$ ).

h, Sample 14a, sediment (a $5-\mu \mathrm{l}$ portion of $10.05 \mathrm{mg}$ per $402 \mu \mathrm{l}$ ).

Chromatograms for the unstable amino acids asparagine, cysteine,
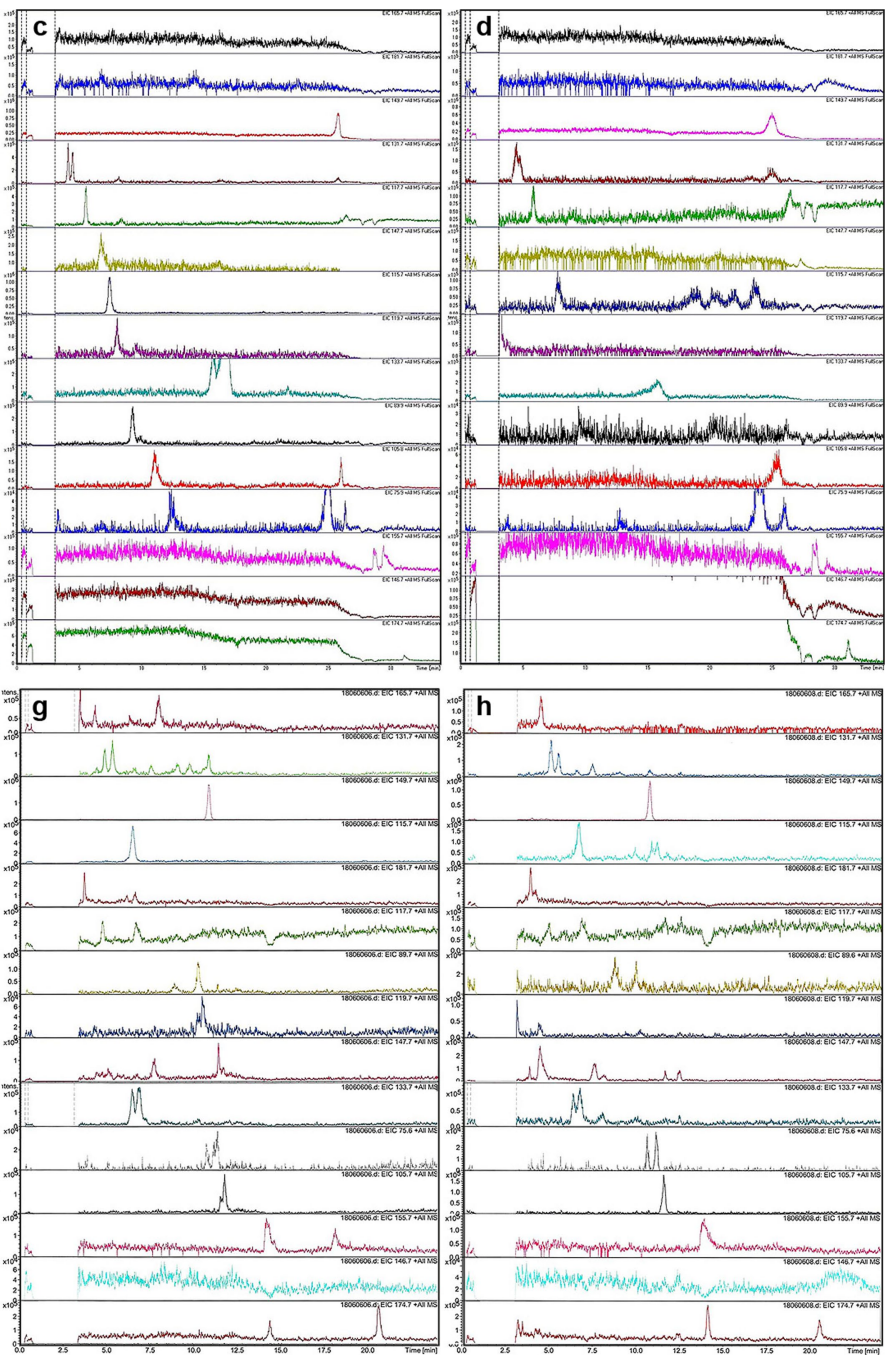

glutamine and tryptophan were omitted from the figure. Additionally, aspartic acid, methionine and tyrosine were not detected (either owing to their low ionization efficacy or lability). Peaks with retention times similar to those of glycine and serine in the condition-II chromatograms derive from impurities (as demonstrated by the corresponding amino acid peaks in the condition-I chromatograms). Data from condition I were used for alanine, glutamic acid, glycine and serine; data from condition II were used for all other amino acids. The solvent for standard amino acids and extracted samples was $0.1 \mathrm{M} \mathrm{HCl}$. hSer, homoserine. ' $\mathrm{x}$ ' denotes an impurity. 


\section{a}

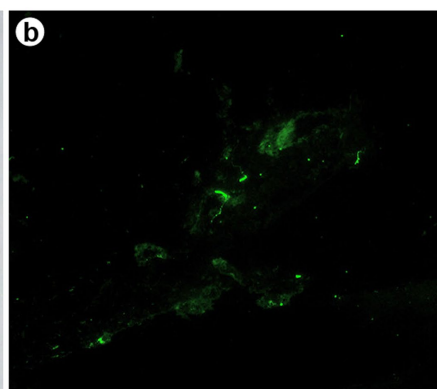

e

\section{i}

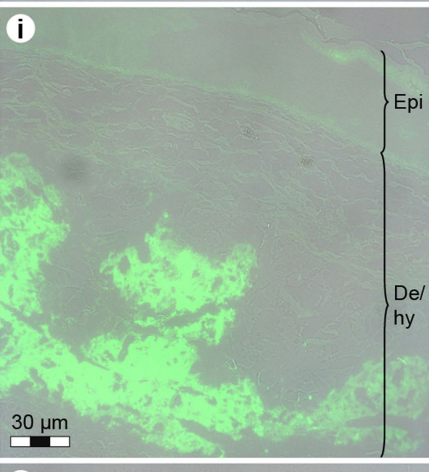

m

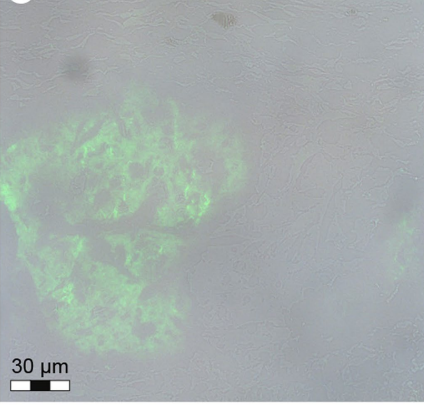

q

r

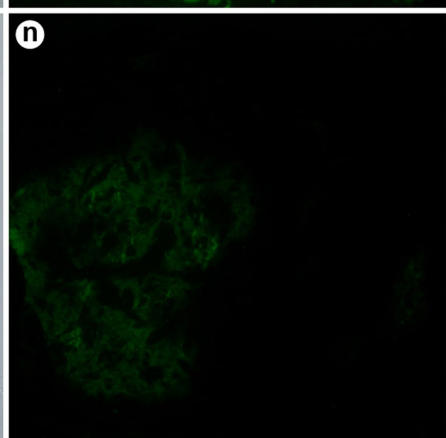

(n)

(j)
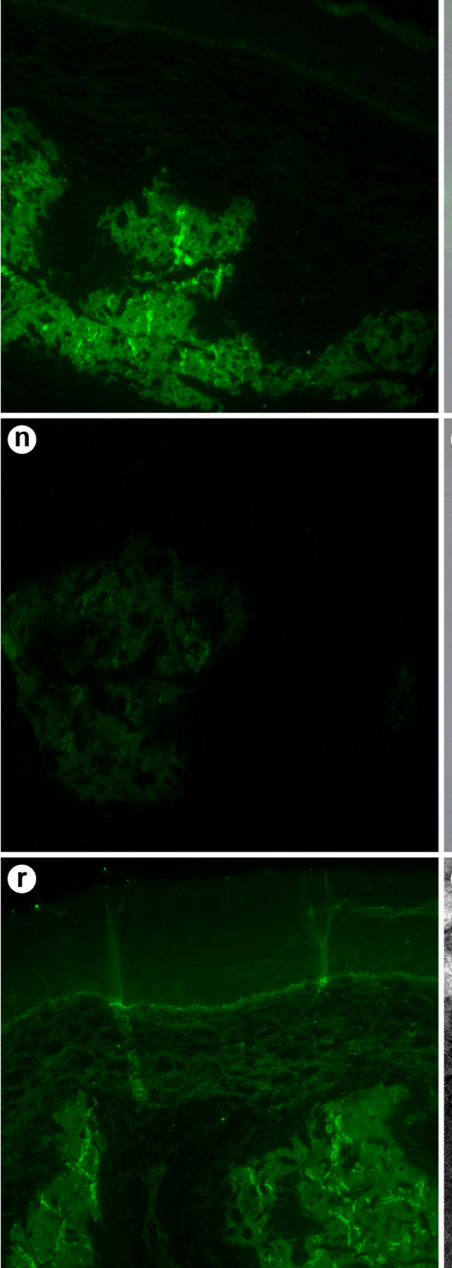

$30 \mu \mathrm{m}$

Extended Data Fig. 7 | Immunoreactivity of fossil ichthyosaur and extant leatherback sea turtle skin. a-t, Immunohistochemical staining and immunogold labelling of demineralized MH 432 skin (samples 8 and 12a) $(\mathbf{a}-\mathbf{h})$ versus experimentally treated $D$. coriacea skin $(\mathbf{i}-\mathbf{t})$, exposed to antibodies raised against Bos taurus elastin (a, b), G. domesticus actin (c, d), A. mississippiensis collagen $(\mathbf{e}, \mathbf{f}, \mathbf{k}, \mathbf{l}), G$. domesticus feathers (indicative of $\beta$-keratin) $(\mathbf{g}, \mathbf{h}), G$. domesticus tropomyosin $(\mathbf{i}, \mathbf{j})$,

A. mississippiensis haemoglobin $(\mathbf{m}, \mathbf{n})$, S. camelus haemoglobin $(\mathbf{o}, \mathbf{p})$ and G. domesticus $\alpha$-keratin $(\mathbf{q}-\mathbf{t})$. Images in $\mathbf{a}, \mathbf{c}, \mathbf{e}, \mathbf{g}, \mathbf{i}, \mathbf{k}, \mathbf{m}, \mathbf{o}, \mathbf{q}$ show where the antibodies bind to tissue (green) superimposed on transmitted light
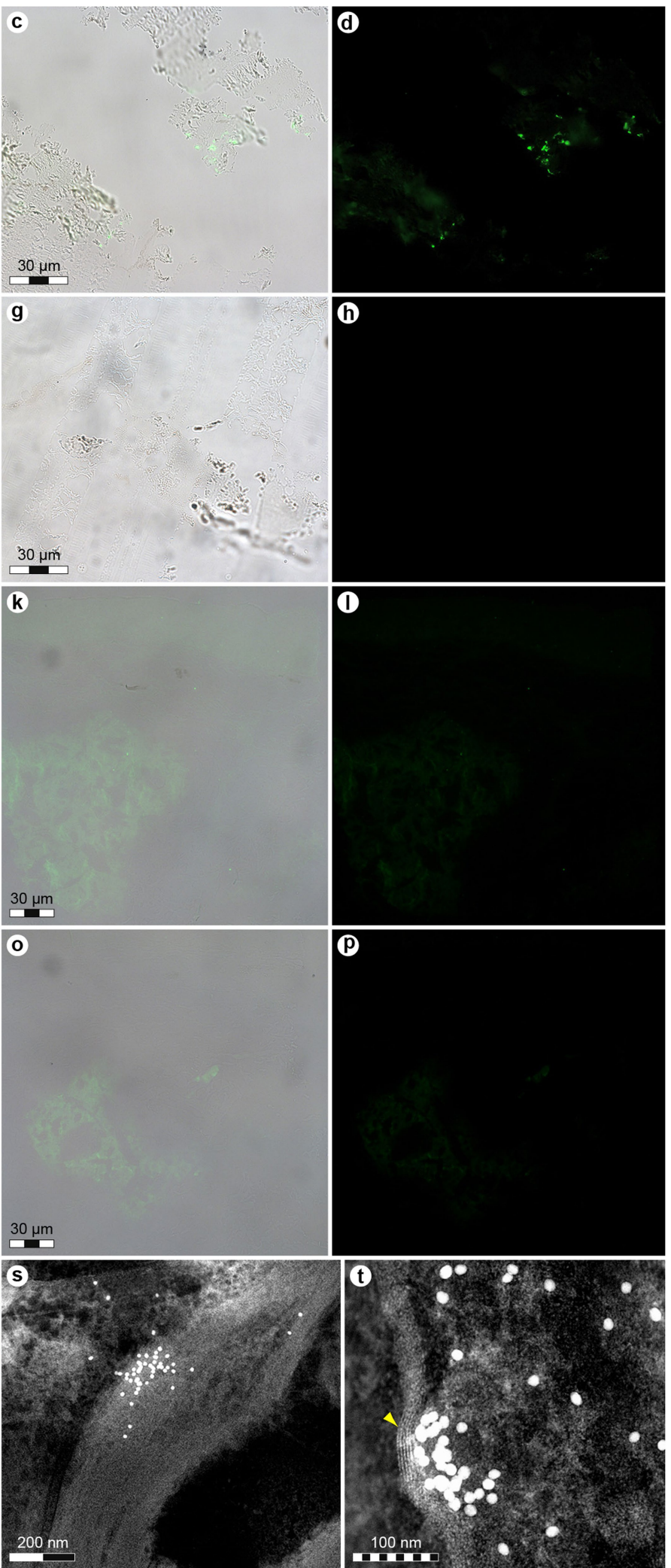

images. Fluorescein isothiocyanate fluorescence in $\mathbf{b}, \mathbf{d}, \mathbf{f}, \mathbf{h}, \mathbf{j}, \mathbf{l}, \mathbf{n}, \mathbf{p}, \mathbf{r}$ indicates binding for all antibodies except $\beta$-keratin. In D. coriacea,

the migration from the epidermis to underlying tissues of compounds derived from $\alpha$-keratin probably reflects the combined effects of decay, compaction and maturation. De/hy, dermis and hypodermis (corresponding to blubber in adult $D$. coriacea); epi, epidermis. $\mathbf{s}, \mathbf{t}$, Low-resolution (s) and high-resolution $(\mathbf{t})$ localization of anti- $\alpha$-keratin antibody tagged with gold to fibrous matter in D. coriacea skin. Note the filamentous structures (arrowhead). 


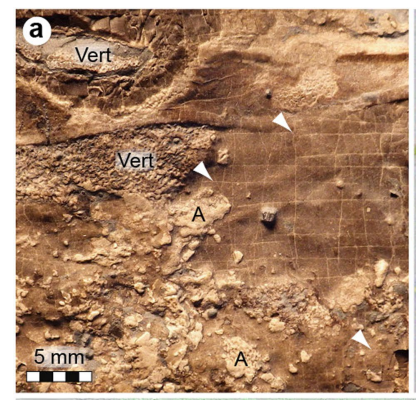

e
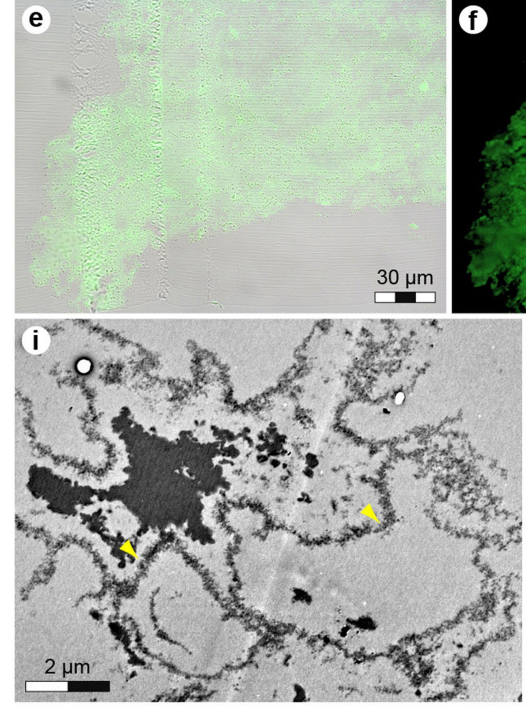

Extended Data Fig. 8 | Ultrastructure and chemistry of the liver of MH 432. a, Polygonal surface structure of the red-brown organ trace (arrowheads). Note the irregular patches of phosphatized adipocere (A) overlying the mineralized internal structure, and a vertebral centrum (vert) that has penetrated the decomposing tissue before fossilization. b, Light microscopy section through demineralized liver matrix (sample 1), which reveals its layered architecture that is probably produced by diagenetic compaction. c, FEG-SEM micrograph of pliable organic matter
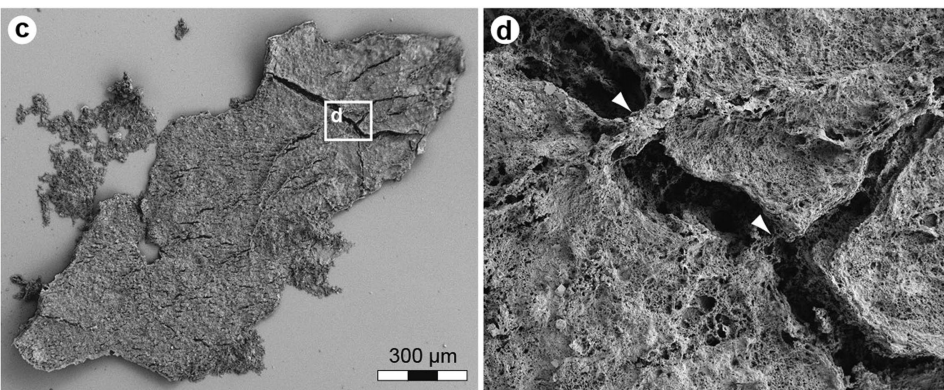

g
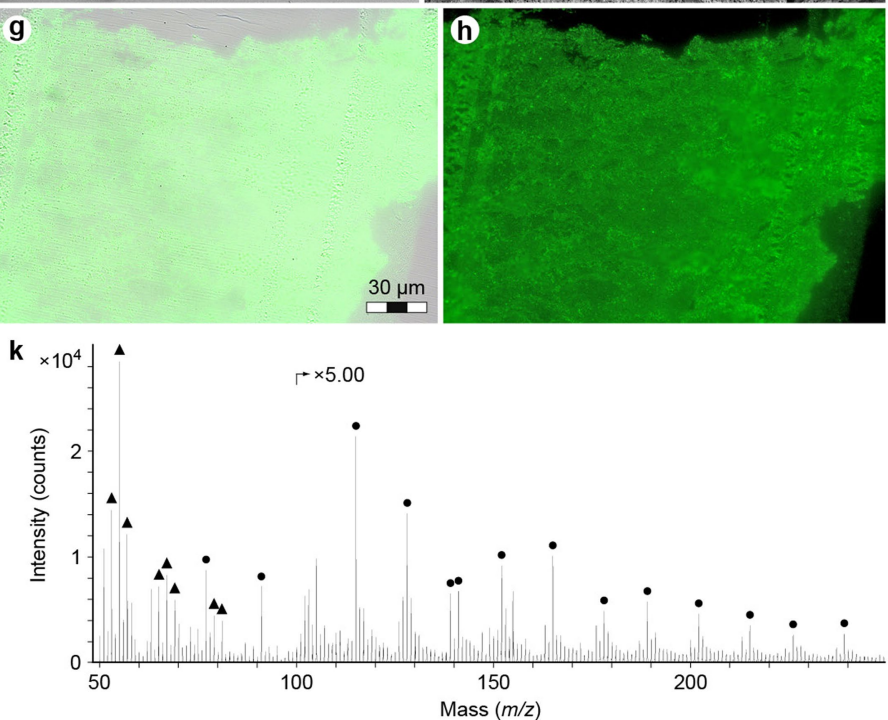

released via treatment with EDTA (sample 1). d, Enlargement showing a degraded and somewhat fibrous (arrowheads) biomass. e-h, Overlay (e, $\mathbf{g}$ ) and fluorescent $(\mathbf{f}, \mathbf{h})$ images of demineralized liver material (sample 7) exposed to antibodies raised against $A$. mississippiensis (e, f) and $S$. camelus haemoglobin $(\mathbf{g}, \mathbf{h})$. i, TEM micrograph of probable cellular membranes (arrowheads). j, TEM micrograph showing a dense melanosome cluster (sample 1). k, Positive ion ToF-SIMS spectrum with peaks characteristic of aliphatics (triangles) and polyaromatics (circles; sample 1). 

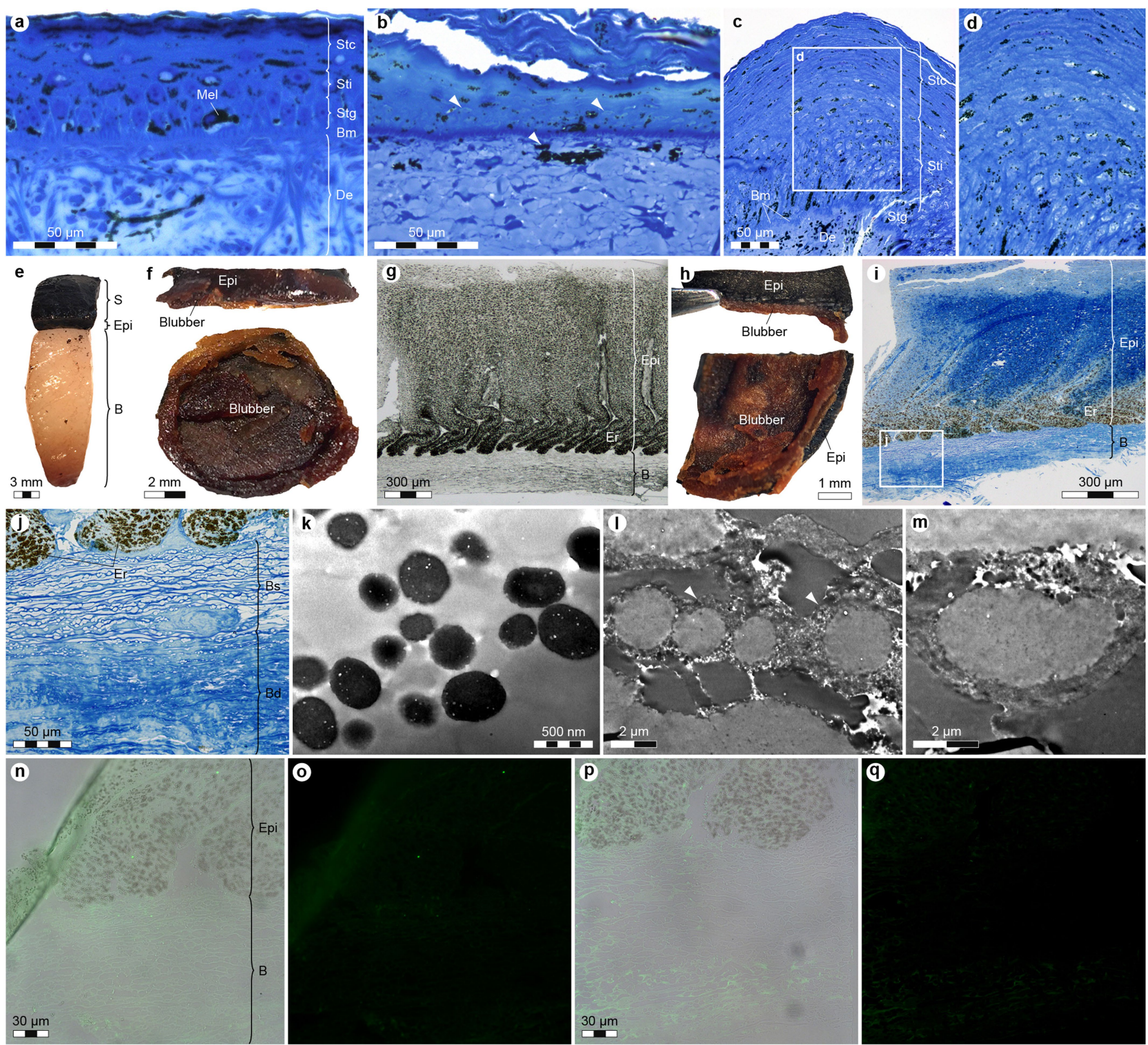

Extended Data Fig. 9 | Experimental maturation of extant skin and subcutis to simulate the effects of diagenesis. a, Stained light microscopy section through the scaly carapace integument from a juvenile $D$. coriacea. $\mathrm{Bm}$, basement membrane; de, dermis; mel, melanophore; stc, stratum corneum; stg, stratum germinativum; and sti, stratum intermedium. b, Autoclave-treated carapace integument from a juvenile $D$. coriacea showing flattened keratinocytes and melanophores (arrowheads). c, Scaleless carapace integument of an adult $D$. coriacea revealing multiple layers of stratified squamous keratinocytes. Note the greater thickness of the stratum intermedium in the adult relative to the juvenile individual (compare with a). d, Enlargement of the stratum corneum and stratum intermedium. e, Melanized P. phocoena body integument. B, blubber (dermis and subcutis); epi, epidermis; s, outer skin surface (in oblique aspect). f, Side (top) and internal (bottom) views of artificially compressed

P. phocoena integument. g, Light microscopy section through artificially compressed $P$. phocoena integument showing the condensed blubber layer (compare with e). Er, epidermal ridge. h, Side (top) and internal (bottom) views of $P$. phocoena integument following autoclave experiments.

i, Stained light microscopy section through autoclave-treated integument of $P$. phocoena. j, Enlargement of the loosely packed superficial blubber (Bs) - a possible entry for microbes (compare Extended Data Fig. 10d) and dense deeper blubber (Bd). k, Melanosomes in experimentally treated epidermis of $P$. phocoena. l, m, Shrunken, membrane-bound (arrowheads) adipocytes (or lipid vesicles) in experimentally treated blubber of P. phocoena (compare Extended Data Fig. 10g). n-q, Overlay (n, p) and fluorescent $(\mathbf{o}, \mathbf{q})$ images of experimentally treated integument of $P$. phocoena, exposed to antibodies raised against $G$. domesticus $\alpha$-keratin $(\mathbf{n}, \mathbf{o})$ and G. domesticus tropomyosin $(\mathbf{p}, \mathbf{q})$. 

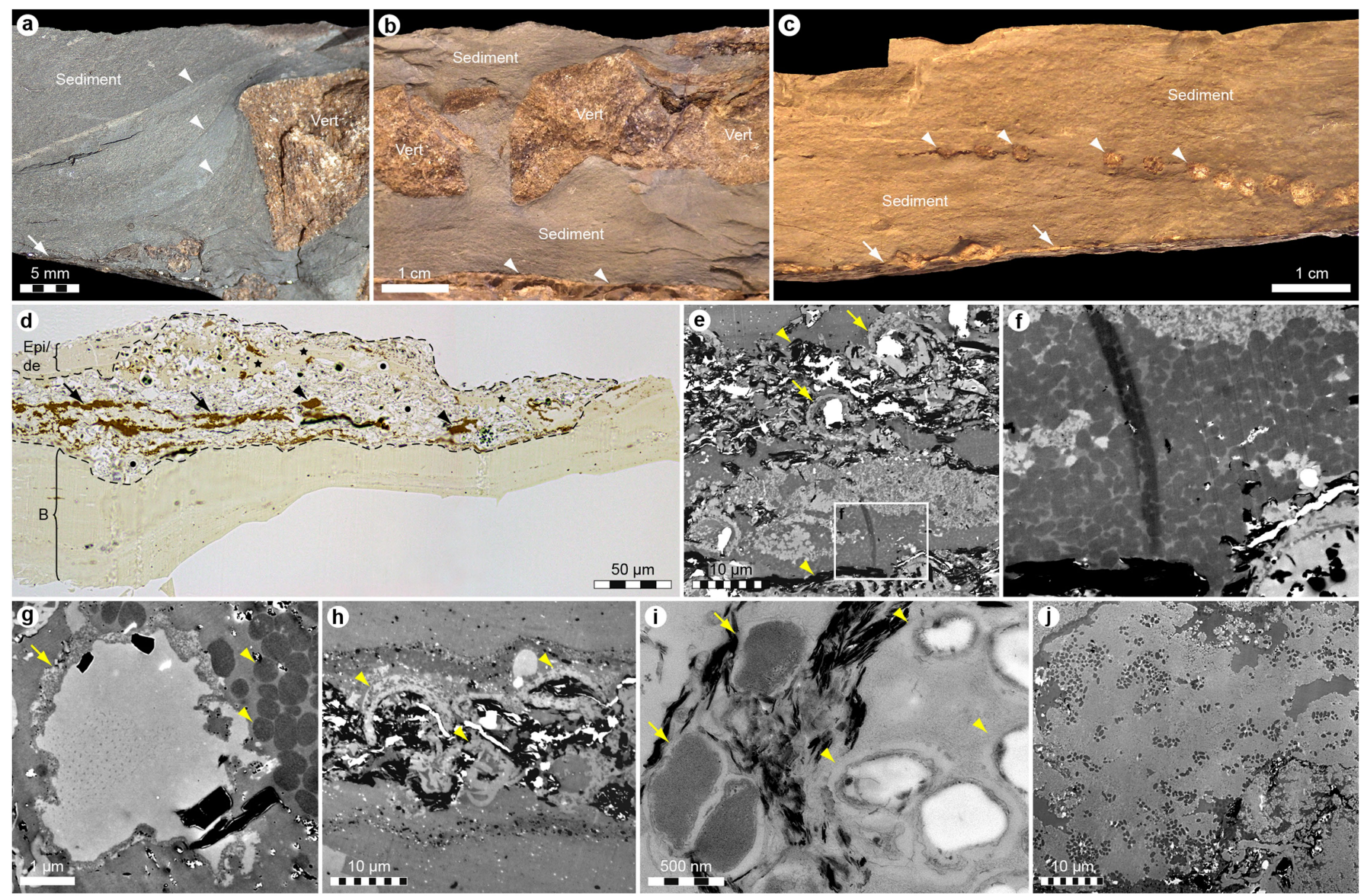

Extended Data Fig. 10 | Taphonomy of MH 432. a, Cross-section through the main rock slab (left side of posterior termination) in original geological orientation, showing sediment infill between the integument (arrow) and a sectioned vertebra (vert). Saturated mud (arrowheads) encased the carcass following gravitational collapse of the backbone. b, Natural break through the main slab (centre of posterior termination) exposing intrusive sediment infill into the body cavity before disarticulation of the vertebral column. Arrowheads indicate the liver residue. c, Cross-section through the main slab (right side of posterior termination). Note the invasive sediment covering the residual soft parts (arrows) and dorsal ribs from the right side of the body (arrowheads). d, Light microscopy section through demineralized integument (sample 13a) with clay minerals and inferred bacteria (delimited by dashed line) penetrating between the phosphatized epidermis and/or dermis (Epi/de)

and polymerized blubber (B). Skin (stars) and melanophores (arrowheads) occur along with hollow structures interpreted as bacterial cellular bodies (circles) and massed melanosomes (arrows). e, TEM micrograph of sample 13a showing clay minerals (arrowheads) and bacterial cells (arrows). f, Enlarged melanosome concentration produced by microbially mediated skin reduction. g, Adipocyte or lipid vesicle (compare Extended Data Fig. 9l, m), or microbe (compare with i), with well-developed cellular membrane (arrow) and adjacent melanosomes (arrowheads). h, Collapsed thick-walled bacterial cells (arrowheads) that suggest microorganismal infestation before fossilization and diagenetic compaction (sample 13a). i, Comparative image of extant bone-boring bacteria (arrows) showing retention of cellular membranes (arrowheads) after removal of internal contents. j, Decomposed skin of MH 432 (sample 13). 


\section{Reporting Summary}

Nature Research wishes to improve the reproducibility of the work that we publish. This form provides structure for consistency and transparency in reporting. For further information on Nature Research policies, see Authors \& Referees and the Editorial Policy Checklist.

\section{Statistical parameters}

When statistical analyses are reported, confirm that the following items are present in the relevant location (e.g. figure legend, table legend, main text, or Methods section).
n/a $\mid$ Confirmed
$\square \bigotimes$ The exact sample size $(n)$ for each experimental group/condition, given as a discrete number and unit of measurement
$\square$ \ An indication of whether measurements were taken from distinct samples or whether the same sample was measured repeatedly
$\searrow$ The statistical test(s) used AND whether they are one- or two-sided
$\triangle \square$ Only common tests should be described solely by name; describe more complex techniques in the Methods section.
Х $\square$ A description of all covariates tested
Х $\square$ A description of any assumptions or corrections, such as tests of normality and adjustment for multiple comparisons
$\square \bigotimes \begin{aligned} & \text { A full description of the statistics including central tendency (e.g. means) or other basic estimates (e.g. regression coefficient) AND } \\ & \text { variation (e.g. standard deviation) or associated estimates of uncertainty (e.g. confidence intervals) }\end{aligned}$
$\bigotimes \square \square \begin{aligned} & \text { For null hypothesis testing, the test statistic (e.g. } F, t, r \text { ) with confidence intervals, effect sizes, degrees of freedom and } P \text { value noted } \\ & \text { Give } P \text { values as exact values whenever suitable. }\end{aligned}$
Х $\square$ For Bayesian analysis, information on the choice of priors and Markov chain Monte Carlo settings
Х $\square$ For hierarchical and complex designs, identification of the appropriate level for tests and full reporting of outcomes
$\bigotimes \square$ Estimates of effect sizes (e.g. Cohen's $d$, Pearson's $r$ ), indicating how they were calculated
Х $\square$ Clearly defined error bars
State explicitly what error bars represent (e.g. SD, SE, CI)

Our web collection on statistics for biologists may be useful.

\section{Software and code}

Policy information about availability of computer code

Data collection LM: Lumenera Infinity Analyze, version 6.4.1 software (for imaging)

FEG-SEM: Zeiss SmartSEM v05.04.05.00 and (EDX) Aztec version 3.3, Oxford Instrument Nanotechnology Tools Limited

TEM: TEM Centre for JEM1400 Plus software (for imaging)

ToF-SIMS: SurfaceLab, version 6.7 (IONTOF GmbH, Münster, Germany)

Py-GC/MS: Varian MS Workstation, version 6.8 (Varian Inc., Palo Alto, USA)

IHC: image data collected using the Axiovision software package (version 4.7.0.0)

IR microspectroscopy: Bruker OPUS 7.5 (Bruker, Ettlingen, Germany), Agilent Resolutions Pro 5.3.0.1694 (Agilent Technologies Inc.)

NanoSIMS: NS50L version 4.4 on Windows 764 bit platform

Data analysis FEG-SEM/EDX: Aztec version 3.3, Oxford Instrument Nanotechnology Tools Limited

ToF-SIMS: SurfaceLab, version 6.7 (IONTOF GmbH, Münster, Germany)

Py-GC/MS: Varian MS Data Review, version 6.8 (Varian Inc., Palo Alto, USA)

NanoSIMS: ImageJ software, using the OpenMIMS plugin (for image processing)

IR microspectroscopy: Bruker OPUS 7.5 (Bruker, Ettlingen, Germany), Agilent Resolutions Pro 5.3.0.1694 (Agilent Technologies Inc.)

SRXTM: Voxler 2 and 3

SRS-XRF: MicroAnalysis Toolkit (www.sams-xrays.com/smak)

For manuscripts utilizing custom algorithms or software that are central to the research but not yet described in published literature, software must be made available to editors/reviewers upon request. We strongly encourage code deposition in a community repository (e.g. GitHub). See the Nature Research guidelines for submitting code \& software for further information. 
Policy information about availability of data

All manuscripts must include a data availability statement. This statement should provide the following information, where applicable:

- Accession codes, unique identifiers, or web links for publicly available datasets

- A list of figures that have associated raw data

- A description of any restrictions on data availability

The specimen of this study ( $\mathrm{MH} 432$ ) is accessioned in the collections at Urweltmuseum Hauff, Holzmaden, Germany. The data that support the findings of this study are available from the corresponding author upon reasonable request.

\section{Field-specific reporting}

Please select the best fit for your research. If you are not sure, read the appropriate sections before making your selection.

$\bigotimes$ Life sciences $\quad \square$ Behavioural \& social sciences

For a reference copy of the document with all sections, see nature.com/authors/policies/ReportingSummary-flat.pdf

\section{Life sciences}

\section{Study design}

All studies must disclose on these points even when the disclosure is negative.

Sample size We provide an ultrastructural and biochemical investigation of a single fossil specimen: MH 432 (Stenopterygius).

Data exclusions No data were excluded from the analyses.

Replication As described in our 'Methods' section (notably in the new 'Statistics and reproducibility' paragraph) and 'Supplementary Information', almost all of our experiments (including LM, FEG-SEM, EDX, TEM, IHC, SRXTM, IR microspectroscopy, NanoSIMS, ToF-SIMS, Py-GC/MS, AHPO, and AAA) were replicated (often multiple times) with similar results. Those experiments that were not repeated include SRS-XRF and UV imaging of MH 432, the artificial maturation of the extant Phocoena integument, and TEM of bacteria.

Randomization Not relevant to this study. We have a limited number of unique samples (from a single specimen) and corresponding control experiments.

Blinding Not relevant to this study. We have a limited number of unique samples (from a single specimen) and corresponding control experiments.

\section{Materials \& experimental systems}

Policy information about availability of materials
$\mathrm{n} / \mathrm{a}$ Involved in the study
\ $\square$ Unique materials
$\square$ Antibodies
Х $\square$ Eukaryotic cell lines
Х $\square$ Research animals
Х $\square$ Human research participants

Antibodies

Antibodies used

G-30 anti-alpha keratin, courtesy of R. Sawyer; anti-bovine elastin, courtesy of R. Mecham; anti-alligator HB, Biosynthesis BSYN6941; anti-ostrich HB, GenScript 70594-1; anti-beta-keratin, Biosynthesis BSYN6734; anti-alligator collagen, Biosynthesis BSYN6959; anti-tropomyosin, Abcam ab11190; anti-chicken actin, Capralogics Inc. P00851; anti-chicken collagen, USBiological C7510-13B; anti-peptidoglycan monoclonal, ABD Serotec 7263-1006; 18 nm Colloidal Gold AffiniPure Donkey Anti-Goat IgG, Jackson Immuno Research Inc. Cat.\# 705-215-147; Biotinylated Goat Anti-Rabbit IgG, Vector BA-1000; Biotinylated Rabbit AntiSheep IgG, Vector BA-6000; Biotinylated Goat Anti-Mouse IgG, Vector BA-9200

Validation

G-30 anti-alpha-keratin - polyclonal, ag=chicken alpha-keratin, host: goat. Alibardi, L. \& DeNardo, D. F. Ultrastructural and immunocytochemical features of the epidermis of the lizard Heloderma suspectum indicate richness in lipids and lack of a specialized shedding complex, Acta Zool. 94, 35-43 (2013).

anti-bovine elastin - polyclonal, ag=bovine elastin, host: rabbit. Cleland, T. P. et al. Mass spectrometry and antibody-based characterization of blood vessels from Brachylophosaurus canadensis. J. Prot. Res. 14, 5252-5262 (2015). Schweitzer, M. H., 
Moyer, A. E. \& Zheng, W. Testing the hypothesis of biofilm as a source for soft tissue and cell-like structures preserved in dinosaur bone. PLoS ONE 11, e0150238 (2016)

anti-alligator HB-polyclonal, ag=alligator hemoglobin, host: rabbit. Lindgren, J. et al. Biochemistry and adaptive colouration of an exceptionally preserved juvenile fossil sea turtle. Sci. Rep. 7, 13324 (2017).

anti-ostrich HB-polyclonal, ag=ostrich hemoglobin, host: rabbit. Schweitzer, M. H., Moyer, A. E. \& Zheng, W. Testing the hypothesis of biofilm as a source for soft tissue and cell-like structures preserved in dinosaur bone. PLoS ONE 11, e0150238 (2016). Lindgren, J. et al. Biochemistry and adaptive colouration of an exceptionally preserved juvenile fossil sea turtle. Sci. Rep. 7, 13324 (2017)

anti-beta-keratin - polyclonal, ag=white chicken feathers, host: rabbit. Moyer, A.E., Zheng, W. \& Schweitzer, M. H. Keratin durability has implications for the fossil record: results from a 10 year feather degradation experiment. PLoS ONE 11, e0157699 (2016). Moyer, A. E., Zheng, W. \& Schweitzer, M. H. Microscopic and immunohistochemical analyses of the claw of the nesting dinosaur, Citipati osmolskae. Proc. R. Soc. B 283, 20161997 (2016). Pan, Y. H. et al. Molecular evidence of keratin and melanosomes in feathers of the early cretaceous bird Eoconfuciusornis. Proc. Natl. Acad. Sci. 113, E7900-E7907 (2016). Lindgren, J. et al. Biochemistry and adaptive colouration of an exceptionally preserved juvenile fossil sea turtle. Sci. Rep. 7, 13324 (2017).

anti-alligator collagen - polyclonal, ag=alligator skin collagen, host: rabbit. Moyer, A. E., Zheng, W. \& Schweitzer, M. H. Microscopic and immunohistochemical analyses of the claw of the nesting dinosaur, Citipati osmolskae. Proc. R. Soc. B 283, 20161997 (2016)

anti-tropomyosin -ab11190: chicken tropomyosin polyclonal, host: rabbit; WB (1:100), ICC/IF (1:40). Goins, L. M. \& Mullins, R. D. A novel tropomyosin isoform functions at the mitotic spindle and Golgi in Drosophila. Mol. Biol. Cell 26, 2491-2504 (2015). Cleland, T. P. et al. Mass spectrometry and antibody-based characterization of blood vessels from Brachylophosaurus canadensis. J. Prot. Res. 14, 5252-5262 (2015). Lindgren, J. et al. Biochemistry and adaptive colouration of an exceptionally preserved juvenile fossil sea turtle. Sci. Rep. 7, 13324 (2017).

anti-chicken actin -P00851: chicken actin polyclonal, host: rabbit; ammonium sulfate fractionation; WB (1:500); IHC (1:100); Pacheco, T. R., Moita, L. F., Gomes, A. Q., Hacohen, N. \& Carmo-Fonseca, M. RNA interference knockdown of hU2AF35 impairs cell cycle progression and modulates alternative splicing of Cdc25 transcripts. Mol. Biol. Cell 17, 4187-4199 (2006). Yuan, D., Liu, L. \& Gu, D. Transcriptional regulation of livin by beta-catenin/TCF signaling in human lung cancer cell lines. Mol. Cell Biochem. 306, 171-178 (2007). Cleland, T. P. et al. Mass spectrometry and antibody-based characterization of blood vessels from Brachylophosaurus canadensis. J. Prot. Res. 14, 5252-5262 (2015). Schweitzer, M. H., Moyer, A. E. \& Zheng, W. Testing the hypothesis of biofilm as a source for soft tissue and cell-like structures preserved in dinosaur bone. PLoS ONE 11, e0150238 (2016).

anti-chicken collagen - polyclonal, chicken collagen type I, host: rabbit, E, IF (1:80), IHC(1:1000), RIA. Schweitzer, M. H. et al. Biomolecular characterization and protein sequences of the campanian hadrosaur B. canadensis. Science 324, 626-631 (2009). Moyer, A. E., Zheng, W. \& Schweitzer, M. H. Microscopic and immunohistochemical analyses of the claw of the nesting dinosaur, Citipati osmolskae. Proc. R. Soc. B 283, 20161997 (2016).

anti-peptidoglycan-monoclonal, ag=Streptococcus mutans BHT, host: mouse. Robertson, J. et al. Intestinal APCs of the endogenous nanomineral pathway fail to express PD-L1 in Crohn's disease. Sci. Rep. 6, 26747 (2016). Miklossy, J. Bacterial amyloid and DNA are important constituents of senile plaques: further evidence of the spirochetal and biofilm nature of senile plaques. J. Alzheimers Dis. 53, 1459-1473 (2016). Schweitzer, M. H., Moyer, A. E. \& Zheng, W. Testing the hypothesis of biofilm as a source for soft tissue and cell-like structures preserved in dinosaur bone. PLoS ONE 11, e0150238 (2016). Lindgren, J. et al. Biochemistry and adaptive colouration of an exceptionally preserved juvenile fossil sea turtle. Sci. Rep. 7, 13324 (2017)

$18 \mathrm{~nm}$ colloidal gold affinipure donkey anti-goat IgG - polyclonal, ag=goat IgG(H+L), host: donkey, working dilution: 1:10. Ferrero, S. et al. Proliferation and morphogenesis of the ER driven by the membrane domain of 3-hydroxy-3-methylglutaryl coenzyme A reductase in plant cells. Plant Phys. 168, 899-914 (2015).

biotinylated goat anti-rabbit IgG - polyclonal, ag=rabbit $\lg G(\mathrm{H}+\mathrm{L})$, host: goat, working dilution: 1:500. Cleland, T. P. et al. Mass spectrometry and antibody-based characterization of blood vessels from Brachylophosaurus canadensis. J. Prot. Res. 14, 52525262 (2015). Schweitzer, M. H., Moyer, A. E. \& Zheng, W. Testing the hypothesis of biofilm as a source for soft tissue and cell-like structures preserved in dinosaur bone. PLoS ONE 11, e0150238 (2016). Lindgren, J. et al. Biochemistry and adaptive colouration of an exceptionally preserved juvenile fossil sea turtle. Sci. Rep. 7, 13324 (2017). Lui, S., Torontali, Z., Tadjalli, A. \& Peever, J. Brainstem nuclei associated with mediating apnea-induced respiratory motor plasticity. Sci. Rep. 8, 12709 (2018).

biotinylated rabbit anti-sheep IgG - polyclonal, ag=sheep $\lg G(\mathrm{H}+\mathrm{L})$, host: rabbit, working diluttion 1:500. Douvaras, P. et al. Abnormal corneal epithelial maintenance in mice heterozygous for the micropinna microphthalmia mutation Mp. Exp. Eye Res. 149, 26-39 (2016)

biotinylated goat anti-mouse IgG-polyclonal, ag=mouse IgG(H+L), host: goat. Schweitzer, M. H., Moyer, A. E. \& Zheng, W. Testing the hypothesis of biofilm as a source for soft tissue and cell-like structures preserved in dinosaur bone. PLoS ONE 11, e0150238 (2016). Lindgren, J. et al. Biochemistry and adaptive colouration of an exceptionally preserved juvenile fossil sea turtle. Sci. Rep. 7, 13324 (2017). Lui, S., Torontali, Z., Tadjalli, A. \& Peever, J. Brainstem nuclei associated with mediating apnea-induced respiratory motor plasticity. Sci. Rep. 8, 12709 (2018). 
Method-specific reporting

na Involved in the study

$\square \square$ chlp-seq

Х $\square$ Flow cytometry

$\mathbb{\square} \square$ Magnetic resonance imaging

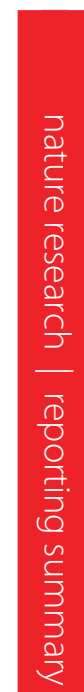

4 